\title{
Stability of Peer Acceptance and Rejection and Their Effect on Academic Performance in Primary Education: A Longitudinal Research
}

\author{
Francisco J. García Bacete ${ }^{1, *,+}+\mathbb{D}$, Victoria Muñoz Tinoco ${ }^{2,+}$, Ghislaine Marande Perrin ${ }^{1,+}+\mathbb{D}$ and \\ Jesús F. Rosel Remírez ${ }^{1}$ (D) \\ 1 Department of Developmental, Educational and Social Psychology and Methodology, Universitat Jaume I, \\ 12071 Castellón de la Plana, Spain; marande@uji.es (G.M.P.); rosel@uji.es (J.F.R.R.) \\ 2 Developmental and Educational Psychology, University of Seville, 41018 Sevilla, Spain; tinoco@us.es \\ * Correspondence: fgarcia@uji.es \\ $+\quad$ Member of GREI group (Grupo interuniversitario de investigación del rechazo entre iguales en contextos \\ escolares; Interuniversity research group on peer rejection in school contexts).
}

Citation: García Bacete, F.J.; Muñoz Tinoco, V.; Marande Perrin, G.;

Rosel Remírez, J.F. Stability of Peer Acceptance and Rejection and Their Effect on Academic Performance in Primary Education: A Longitudinal Research. Sustainability 2021, 13, 2650. https://doi.org/10.3390/su13052650

Academic Editor: Marc A. Rosen

Received: 29 December 2020

Accepted: 24 February 2021

Published: 2 March 2021

Publisher's Note: MDPI stays neutral with regard to jurisdictional claims in published maps and institutional affiliations.

Copyright: (c) 2021 by the authors. Licensee MDPI, Basel, Switzerland. This article is an open access article distributed under the terms and conditions of the Creative Commons Attribution (CC BY) license (https:/ / creativecommons.org/licenses/by/ $4.0 /)$.

\begin{abstract}
The objectives of this study were to analyze the evolution of peer relationships and academic performance and the effect of the former on the latter in primary education, differentiating between positive and negative relationships. To this end, the likes and dislikes received by each student from his/her classmates were measured at four time points between first and sixth grades, as well as the marks given by their teachers in the subjects of mathematics and Spanish language. One-hundred-sixty-nine students ( $52.7 \%$ girls) from 10 classes of five public schools participated in this study. To verify the objectives, we used a complex structural equation model, obtained from a combination of two autoregressive models (AR, one for social preferences and another one for academic performance), two multi-trait multi-method models (MTMM, one for acceptances and rejections and another one for academic performance in mathematics and Spanish language), and an effects model of social preferences on academic performance. This study confirms: (a) The stability of both peer relationships and academic performance throughout childhood; (b) the stable influence of social relationships on academic performance; and (c) the importance of considering acceptance and rejection differentially. This work reveals the failure of the school to address initial disadvantages, and it provides guidelines for early and inclusive interventions.
\end{abstract}

Keywords: peer liking; peer disliking; academic achievement; primary school; social and educational inclusion; peer acceptance; peer rejection; longitudinal structural equations

\section{Introduction}

Establishing positive peer relationships and developing academic skills are two of the fundamental objectives of primary education in the first school years, setting the foundation for adequate growth and later adjustment [1] On the contrary, poor peer relationships and low academic performance are two of the most important factors that lead to school drop-out, as well as precursors of difficulties to find a job and, consequently, to survive [2,3] In this study, we selected acceptance and rejection among peers as indicators of social experience, particularly social status, and academic performance as an indicator of school adjustment.

\subsection{Acceptance and Rejection}

Acceptance and rejection are attitudinal variables that reflect the positive or negative feelings among the members of a group. These feelings were described by Jacob Moreno [4], the creator of sociometry, as two related forces of different nature. Acceptance would be a set of positive forces that keep people united, whereas rejection would tend to keep people 
separated [5,6]. Acceptance ad rejection are directly related to the basic social need to belong. Thus, an important part of child and adult behavior occurs as a result of the search for acceptance and/or the avoidance of rejection from others [7].

\subsubsection{Acceptance and Rejection: Different, Yet Related}

Since the publication of the study of Coie, Dodge and Coppottelli [8], the construct of social preference has been generally used as a measure of social acceptance and/or social status within a group. Social preference is, conceptually, a very useful construct, although it comes with great methodological difficulties. It is considered a measure of relative acceptance, since it is the result of the difference between the number of acceptances (likes) and the number of rejections (dislikes) that a person receives in a group. However, this combination does not allow analyzing the differential role of the likes and dislikes received [9]. Another problem of using social preference is that it does not seem appropriate to merely subtract or add the scores of likes and dislikes, since these variables are distributed differently, with the rate and variance of likes being greater and lower, respectively, than those of dislikes [10,11]. García Bacete and Cillessen [10] found that social preference is more related to acceptance than to rejection. Other authors have chosen to use only the positive dimension, thus discarding the "rejection" component. However, nowadays there is consensus on the use of bidimensional evaluation systems that consider both the positive and negative nominations, proposing their simultaneous use instead of a combination of them [10].

Already in the 1980s, researchers found that negative nominations could be independent of positive nominations $[12,13]$ In this line, it has been reported that the correlation between acceptance and rejection is negative and significant, although relatively low (around 0.20) [8,14]. Furthermore, Bukowski et al. [9] proposed and confirmed the hypothesis that acceptance and rejection have a negative and complex relationship. According to these authors, the confirmation of this hypothesis proves that acceptance and rejection are, at the same time, two different dimensions that cannot be separated; thus, if they are treated as totally independent or simply opposed concepts, the dynamics that underlie the experiences of children with their peers are distorted. From a group perspective, the social network theory also provides proof of the importance of considering both dimensions as mechanisms of group dynamics. Therefore, it is understood that both attraction and repulsion determine the stability of groups [15]. In this line, the structural balance theory defends the idea of analyzing the positive and negative links of networks simultaneously [16].

\subsubsection{The Expansiveness of Acceptance with Respect to Rejection or Positive Bias}

Social norms favor positivity and courtesy, thus, in interactions, people tend to prioritize harmony and manners over honesty, since it is uncomfortable to evaluate or make negative comments about others. Positive information about others is more freely shared than negative information. This tendency to highlight positive aspects and avoid referring to negative elements results in benefits for interactions and social relationships, although it also implies a bias in the social perception of oneself and others. On the one hand, social norms that encourage positivity favor a positive perceptive bias toward others and, thus, an also biased behavioral response. Complementarily, these social norms inhibit the social expression of our emotions and negative experiences, and, consequently, we tend to hide these negative states [17]. Considering that our evaluations of others and of their internal states are based on visible aspects, and what we show is usually accompanied by this positive bias, it is not surprising that researchers find systematically greater expansiveness in positive nominations, indicating greater expression and visibility of acceptance than rejection. In fact, sociometric questionnaires show that some children are reluctant to express who they dislike, or the reasons why they dislike a particular classmate [18]. 
1.1.3. The Predictive Power of Acceptance and Rejection Experiences. Negative Asymmetry

Do these two experiences have comparable effects? Among positive social experiences, friendship has been, without a doubt, the most researched construct. Regarding negative social experiences, most studies have been focused on rejection as a social category, and those which include the variable "social acceptance" usually employ scores of social preference.

Blackhart et al. [5] pointed out that negative events cause greater emotional effects than positive events, suggesting that the emotional reaction to rejection would be greater than the emotional reaction to acceptance. These results are in line with those of Labianca and Brass [19], who defined the negative asymmetry bias, establishing that: (1) Negative relationships are different from positive relationships, and (2) negative relationships are more strongly related to socioemotional results and academic performance than positive relationships.

Negative emotions are more intense and longer-lasting than positive emotions [20]. The literature shows that negative events and interactions have a disproportionately greater effect on variables such as satisfaction with life, mood, health, and stress than positive events and interactions $[19,21,22]$. People need a higher proportion of positive feedback than negative feedback in order to both feel happy and have worthwhile relationships [23] (e.g., in marriage, labor relations, parent-child relationships and teacher-student relationships). In fact, the consequences of being rejected are more severe than the potential positive consequences derived from increasing attractions [24].

Another aspect that supports this hypothesis is the theory of the need to belong: If acceptance responds to a basic need, it is logical to think that it produces normative positive effects on development, although not especially positive, as it would cause psychological deficits and maladjustments when such need to belong is threatened by peer rejection [25].

Since the publication of the work of Parker and Asher [26], "Peer Relations and Later Personal Adjustment: Are Low-Accepted Children at Risk?", numerous studies have been focused on the predictive power of rejection, accumulating substantial evidence of its effects: It causes mental health problems [27], delinquency, school drop-out and psychological maladjustments [28], puts children at risk of being victimized [29], and moderately reduces mood and self-esteem [30]. DeWall and Bushman [25] published a thorough review of the numerous effects of rejection on emotional, cognitive, behavioral, and biological aspects. However, the mentioned negative results associated with rejection are not always observed. Thus, from the theories of psychological risk and stress, it has been proposed that it is continuous exposure to negative experiences what poses a real risk to development [31]. DeWall and Bushman [25] suggested that rejection activates mechanisms of emotional regulation that bring positive emotions to the front line, thus protecting the stress derived from rejection. As a conclusion, although there are reasons to think that the effects of rejection are greater than those of acceptance, further studies in this line should consider both experiences in a longitudinal manner in order to confirm this hypothesis.

\subsubsection{The Evolution of Acceptance and Rejection: Stability or Change}

Since the chronicity of rejection is a variable that determines the type and severity of the effects of rejection, it seems important to consider its stability in time. Moreover, since it seems that we must not expect comparable effects of acceptance and rejection on adjustment, we should not expect a similar evolution in time for both experiences. The qualitative work of Wiseman and Duck [32] indicates that the development of negative relationships is a much faster process than the development of positive relationships. It is worth determining whether it is also more stable. The research of Coie and Dodge [33] on the sociometric status development phases showed the stability of social preference in two cohorts of primary education children: One in third grade and the other one in fifth grade. Stability in the fifth graders was maintained for a period of 5 years, whereas in the 
third graders it was remained constant for the first 3 years. Moreover, stability was greater for rejection than for acceptance. Salmivalli and Isaacs [34] found medium-high stability for the rejection scores of children of fifth to seventh grades ( $r=0.55$ between Grades 5-7), reaching almost $r=0.70$ in consecutive years. Will, van Lier, Crone, and Güroğlu [35] conducted a longitudinal follow-up from first to sixth grades, and found a correlation of circa 0.70 between the scores of social preference of consecutive years. Age can play an important role in stability. García Bacete, Marande, and Mikami [36] found moderate correlations in acceptance and rejection in the period between the beginning of first grade and the end of second grade. In addition, as it has been found in later studies, rejection is more transferable from one context to another compared to acceptance [37]. Sandstrom and Coie [38] highlighted the importance of analyzing the evolution of social status from the beginning of group formation, since, in the emergence phase, rejection can become a temporal and circumstantial experience for some children, whereas it is consolidated for others, leading to a cycle of negative social experiences.

\subsection{School Adjustment: Academic Performance}

From a systemic perspective, different aspects can be considered when evaluating school adjustment [1,39]. Among such aspects, some of the most frequently incorporated by researchers are: Negative attitudes toward school (reluctance to go to school and learn, school drop-out, etc.), participation in the classroom (autonomy, cooperative participation, etc.), and academic performance (individual advancements in language, mathematics, etc.).

What are the reasons for selecting academic performance among the different indicators of school adjustment? Low performance is one of the earliest and most visible indicators. Thus, performance problems that prevail in time usually lead to school drop-out, which constitutes a social cost in the long term [2]. The longitudinal study conducted by these authors for 19 years concluded that school abandonment begins with the influence of psychosocial variables, some of which appear before children enter the school. Behavioral problems, poor peer relationships and family variables were the most direct correlatives of school performance and school drop-out. The strong association that they found among these indicators suggests numerous autoregressive and multicausal effects. In this line, they pointed out that peer rejection, low performance and behavioral problems at school appear to be early or "half-way-through" markers of school abandonment.

Regarding the measures that should be used, the meta-analysis of Wentzel, Jablansky, and Scalise [40] demonstrates that the academic performance evaluated by the teacher through different tests is more strongly related to peer acceptance than the results obtained in standardized tests. With respect to school matters, performance in reading and mathematics, which are the most frequently used areas in national and international tests to evaluate school competencies, show a positive and strong association in a consistent and stable manner in time. This strong connection is related to the common cognitive skills that they use and the influence of reading comprehension on mathematical performance, especially on problem solving [41,42].

\subsection{Acceptance and Rejection as Predictors of Performance}

Peer acceptance predicts academic performance $[40,43,44]$, whereas rejection leads to a decrease of the latter [45]. The relationship between acceptance and rejection has been observed from early childhood education to secondary education, regardless of the evaluation method used, i.e., either academic valuations made by the teacher or scores of standardized tests, although this connection is greater with the first measurement method and stronger in primary education than in secondary education, according to the metaanalysis of Wentzel et al. [40]. Similarly, longitudinal studies show the stability of this correlation in time; in fact, the graduation marks in secondary education can be predicted by the academic performance at the beginning of primary education [46]. Failure in peer relationships blocks the learning process and leads to school abandonment [47]. Moreover, low acceptance has been related to school maladjustment, with rejection being one of the 
most robust predictors of willingness to learn and academic performance [48]. Buhs, Ladd, and Herald [29] related early rejection to a decrease of participation in the classroom and an increase of school avoidance, which can alter both the social environment of the classroom and the adaptive responses of children at school.

Greenman, Schneider and Tomada [49] studied the relationship between the stability and change patterns of rejection and academic performance in two scopes: Linguistic-social and mathematical-scientific. They analyzed the changes in the sociometric type (rejected or not rejected) at four time points, separated by a total of 18 months. These authors found that the children who were rejected in the four time points had worse academic performance than the children who stopped being rejected at some point, whereas the children who were stably accepted had better performance than those who had been rejected at some point. Going from "not rejected" to "rejected" was related to a decrease of academic performance, whereas becoming "accepted" was associated with an increase of academic performance. The obtained results were similar for both performance scopes.

Other authors have highlighted the reciprocal effects between peer relationships and academic performance. Veronneau, Vitaro, Brendgen, Dishion, and Tremblay [45], in a longitudinal study from second to seventh grades, concluded that: (1) High performance predicts increases in acceptance and decreases in rejection during primary education; (2) performance is a good predictor of social status in the group of peers; and (3) rejection among peers during childhood can influence the academic future of students.

Although the association of peer acceptance and rejection with academic performance is strongly confirmed, it is necessary to further explore the development of this relationship in time and the differential effect of acceptance and rejection on academic performance [29,49].

\subsection{Our Study}

The present study was focused on the evolution of social relationships, of academic performance, and of the effect of relationships on performance, throughout the whole primary education. To this end, four measurements were conducted throughout primary education (Grades 1st, 2nd, 4th, and 6th) to record the status of social relationships (likes and dislikes received by each student from his/her classmates) and academic performance (marks in mathematics and Spanish language). This aim was divided into 4 objectives:

Objective 1: To analyze the evolution of social peer relationships and academic performance throughout primary education. The goal was to determine whether primary education brings significant changes to the social and academic states with which each child enters compulsory education, as well as the trajectory of such states. This objective continues in Objective 3.

Objective 2: To study the effects of social relationships among peers on academic performance. The goal was to determine whether the preferences among peers influence academic performance in each time point, whether such effect is similar in all time points and whether it is transmitted from one time point to the next, and so on. This objective continues in Objective 3.

Objective 3: To explore the positive bias and/or negative asymmetry of peer relationships, verifying the stability and trajectory of positive and negative relationships and their different contribution on peer preferences and academic performance.

Objective 4: To analyze the multilevel effects. Since the data structure is nested, thus the children (individual, level 1, L1) are grouped in classrooms (classroom, L2), we analyzed whether the obtained model was multilevel.

\section{Materials and Methods}

\subsection{Participants}

The research team used an incidental sampling based on the willingness of schools to participate in this study, which resulted in the selection of four mainstream public schools in Castellón, Spain (10 classrooms). All the participating schools were located in urban areas and enrolled primarily children from families of average socio-economic 
status. As for the ethical compliance, the present study was conducted in accordance with the 1975 Helsinki declaration, and was reviewed and approved by the ethics committee of the university Jaume I (Universitat Jaume I, Spain, date of approval: 3rd July 2017). Participation in the study was voluntary. All subjects gave written informed consent. The required authorizations from the families as well as from the educational inspection services and the management board of schools were obtained.

Throughout the six years of primary education, we collected four waves of data: The first wave at the end of first grade (T1), the second one at the end of the second grade (T2), then at the end of fourth grade (T3) and, lastly, at the end of sixth grade (T4). The total number of students who participated in this study was 290. Most of them were Caucasian (89.6\%), nearly 5\% was from Arabian ethnicity, a broad $4 \%$ was mixed-race, and the rest was Asian. Parents' nationality was Spanish for $74.9 \%$ of the complete sample of participants. The pupils ratio in each classroom ranged from 17 to 26 at T1, T2, and T3 and from 10 to 26 at T4. Despite the fact that more than $95 \%$ of the students completed all the questionnaires at all times (100\% at $T 1$ and $T 2,97 \%$ at $T 3$ and $95.1 \%$ at $T 4)$, complete data were available for only 169 students (58.3\%), since there was a high rate of student mobility. Such mobility was due to several factors: (1) Some students entered the study after it had begun, because they were repeating a year; (2) some students who entered the study had to leave before it finished because they had to repeat a year; and (3) many children left the participating schools for reasons of internal migration in Spain or return to their countries of origin, since the study was conducted during years of economic crisis. A large majority of the 169 students that participated in the longitudinal sample was of Caucasian ethnicity (97\%), and their parents' nationality was Spanish for $84.6 \%$ of them.

At T1, the 169 participants of the longitudinal group (89 girls, 52.7\%) were six years old $\left(M_{\text {LongitudinalT1 }}=80.53\right.$ months, $S D_{\text {LongitudinalT1 }}=3.34 ; M_{\text {LongitudinalGirlsT1 }}=80.36$ months, $S D_{\text {LongitudinalGirlsT1 }}=3.36 ; M_{\text {LongitudinalBoysT1 }}=80.72$ months, $S D_{\text {LongitudinalBoysT1 }}=3.33$; $M_{\text {LongitudinalT2 }}=94.53$ months; $M_{\text {LongitudinalT3 }}=118.53$ months; $M_{\text {LongitudinalT4 }}=142.53$ months) . The total sample of children present at $T 1(n=229,49.8 \%$ girls $)$ showed no differences of age with the subsample of the participants in the longitudinal study: $M_{\mathrm{T} 1}=80.52$ months, $S D_{\mathrm{T} 1}=3.33 ; M_{\mathrm{GirlsT} 1}=80.34$ months, $S D_{\mathrm{GirlsT} 1}=3.34 ; M_{\mathrm{Boys} 1}=80.72$ months, $S D_{\text {BoysT1 }}=3.33$. However, the total sample of students present at T4 $(\mathrm{n}=206,52.9 \%$ girls $)$ were slightly older $\left(M_{\mathrm{T} 4}=143.63\right.$ months, $S D_{\mathrm{T} 4}=4.77, M_{\mathrm{GirlsT} 4}=143.51$ months, $S D_{\mathrm{GirlsT} 4}=4.82$; $M_{\text {BoysT4 }}=143.75$ months, $S D_{\text {BoysT4 }}=4.74$ ) than the subsample of the students who participated in the longitudinal group, due to the presence of repeater students in the same school between $T 1$ and T4 or the arrival of older students from other schools. That is, the students belonging to the non-longitudinal sample who were present at $T 4(n=37)$ were significantly older $\left(M_{\text {NonLongitudinalT4 }}=148.62\right.$ months, $\left.S D_{\text {NonLongitudinalT4 }}=6.88, t_{(204)}=8.046\right)$ than the 169 students of the longitudinal group.

We conducted one-way ANOVAs to compare the mean differences between the longitudinal group that provided all the data $(n=169)$ and those subjects who joined after T1 or left school at some point before T4 and were only present in the study in one, two, or three of the four measurements $(n=121)$. The results showed significant mean differences between the longitudinal group and the non-longitudinal group in all variables and waves, yielding $F$-values between 6.190 and 65.405 and $p$-values between 0.000 and 0.014. In the four waves, the subjects of the longitudinal group received more likes and fewer dislikes, and their marks in mathematics and language were better than those of the non-longitudinal group.

\subsection{Measures}

The participants were assessed in peer relationships through sociometric questionnaires and in academic performance through their marks in mathematics and Spanish language.

Sociometric questionnaire for unlimited peer nominations [50]. We showed to each child a set of photos of their classroom peers and asked: "From all the girls and boys in your class, 
whom do you like the most?", and "From all the girls and boys in your class, whom do you like the least?". We then used the Sociomet program [51] to calculate the following two sociometric indices: The index of Positive Nominations Received (PNR/n-1)*100 and the index of Negative Nominations Received (NNR/n-1)*100, which indicate peer acceptance (Likes) and peer rejection (Dislikes), respectively. These indices are percentages in which the denominator is the number of students in the classroom minus $1(n-1)$. Thus, the score ranges between 0 and 100. The validity of this method has been demonstrated in several studies $[10,52]$.

Academic performance. We used the marks obtained by the subjects in mathematics and Spanish language in the end-of-year exams at 1st, 2nd, 4th, and 6th grades, applying a 5-point scale (fail, pass, good, very good and excellent). Studies including academic performance as a dependent variable generally use marks in mathematics and language, and some studies even used an estimate of these marks instead of the actual marks (e.g., [53]).

\subsection{Model}

The M1 structural equation model (SEM) tested in this study is represented in Figure 1; it includes the abovementioned objectives and the hypotheses of this investigation [54-57]. The observable variables or indicators are represented inside rectangles and the factors or latent variables inside ovals, whereas the effects are shown as arrows and the covariances as double arrows. For the sake of simplicity, neither the errors nor the intercepts of each variable are represented. Due to the fact that the text of each variable inside its rectangle or oval was not visible, we decided to use acronyms for some of the variables.

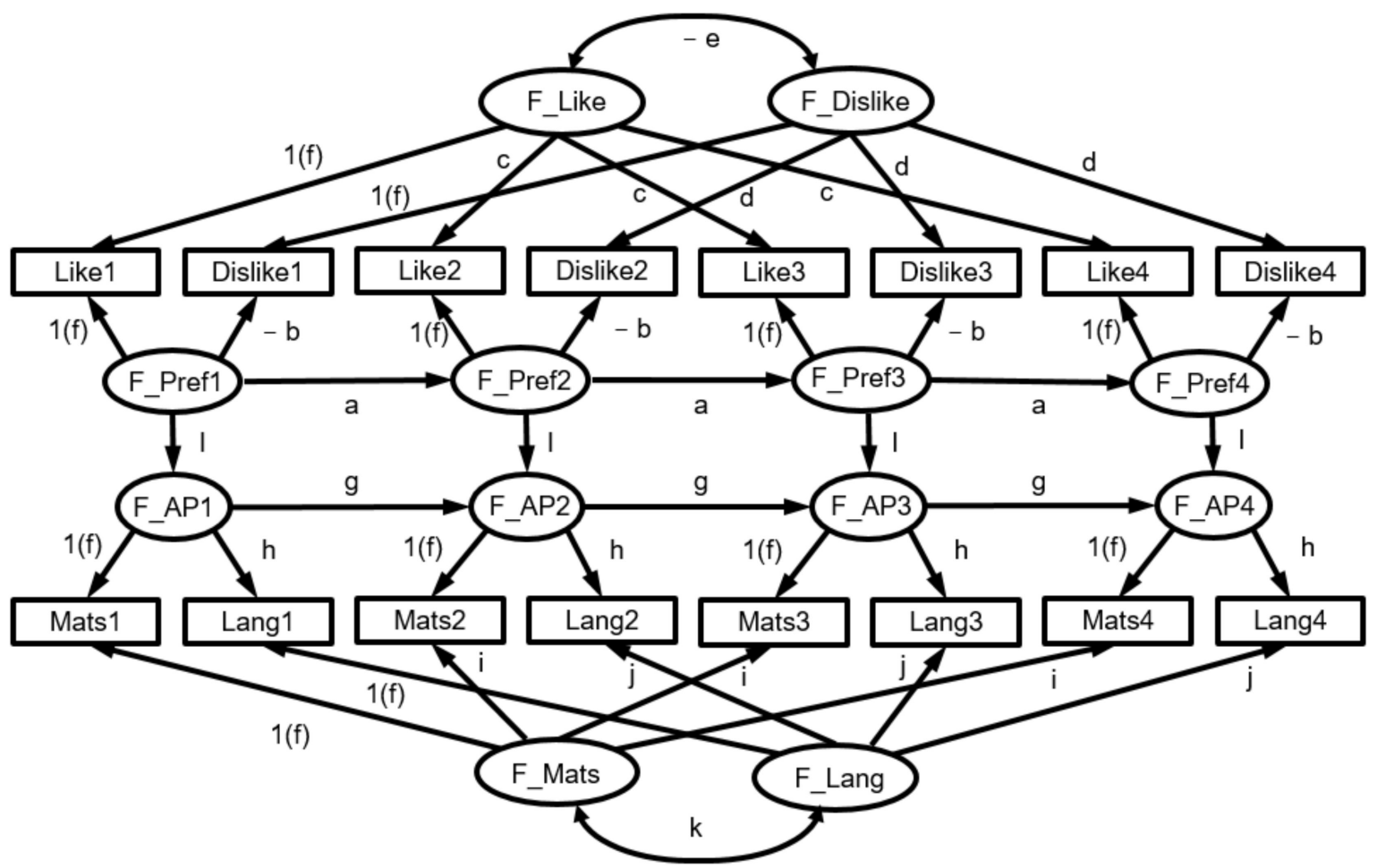

Figure 1. Representation of the effects model proposed in the hypotheses. Notes. The errors of the variables $\left(E_{j}\right)$ and of the factors $\left(D_{k}\right)$ are not represented, in order to keep the figure simple. The effects identified with 1(f) indicate that they are values fixed to 1 , to ensure the convergence of the model; the rest of the effects and covariances are free, although with values " $a$ ", " $b$ ", ..., "l" constrained to be equal.

This model is a combination of the so-called autoregressive (AR) dynamic factor models, multi-trait multi-method models (MTMM) models, and structural models of temporal effects (see Figure 2). The AR submodels for the variables about social relationships and academic performance are shown in Figure 2a,b, respectively. The MTMM mod- 
els for the variables about social relationships and academic performance are shown in Figure $2 c, d$, respectively. These models could actually be denominated as multi-trait multi-time (MTMT). The structural model of the effect of social relationships on academic performance is shown in Figure 2e.

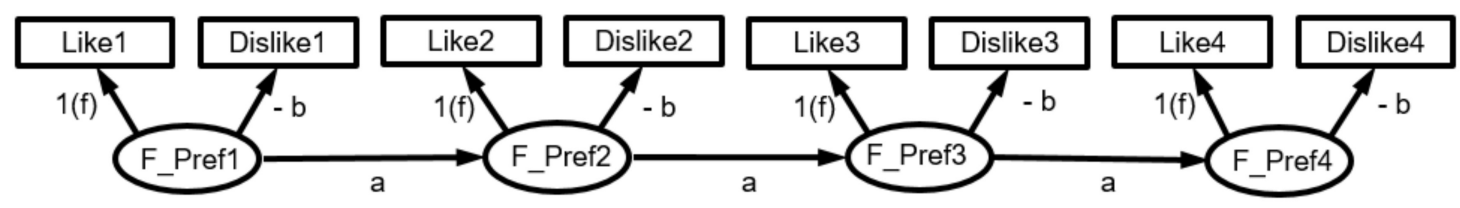

(a)

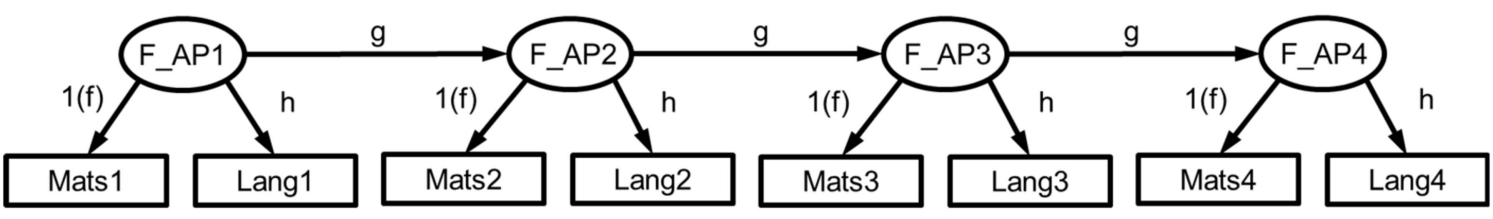

(b)

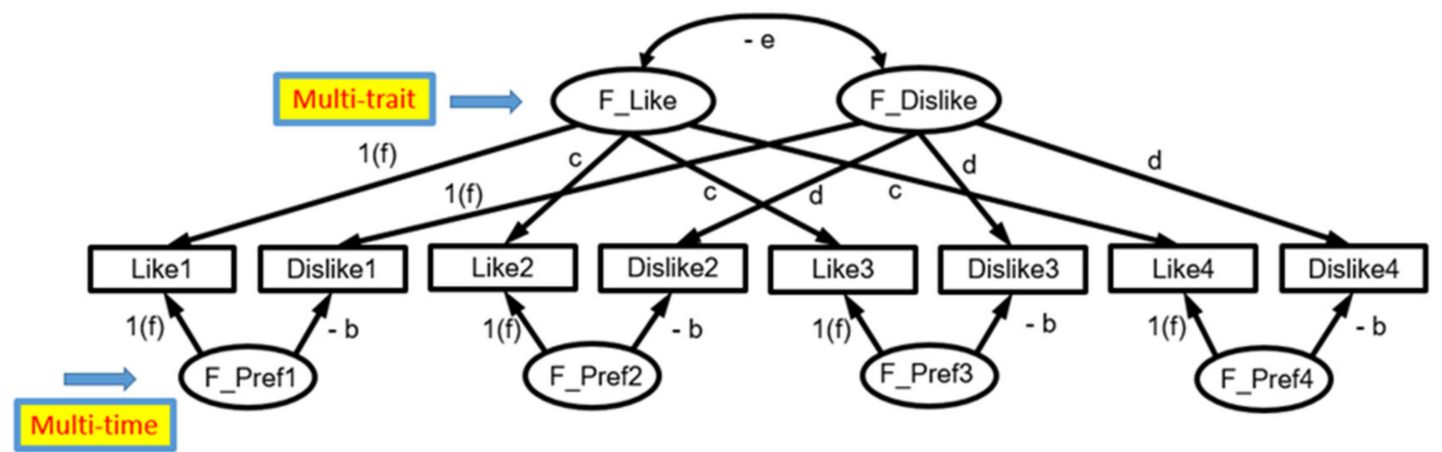

(c)

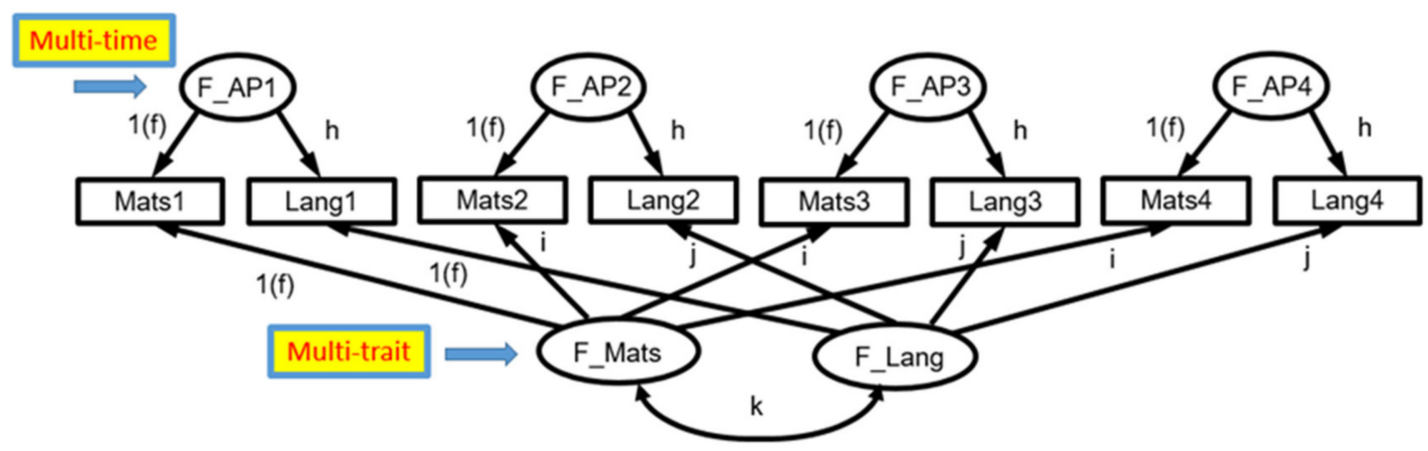

(d)
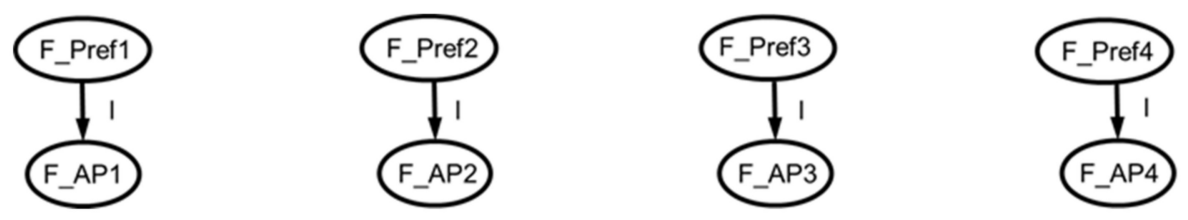

(e)

Figure 2. Representation of the submodels present in Figure 1. (a) AR dynamic factor model of the latent variables of social relationships; (b) AR model of the latent variables of academic performance; (c) MTMT model for the variables of social relationships; (d) MTMT model for the variables of academic performance; (e) structural model of temporal effects between social preference and academic performance. 
In $\mathrm{M} 1$, each observable variable is the result of a factor in each time point and of a representative factor of the variable along time. In the case of social relationships, the indicators are the variables LikeT and DislikeT in each time point $(T=1,2,3$, and 4$)$, which are influenced by the temporal factors PreferenceT of the four measurement time points $\left(F \_\right.$PrefT), of the factor Like (F_Like) and of the factor Dislike (F_Dislike), leaving the covariance between both factors free, expecting it to be negative (parameter " $-e$ " in Figures 1 and 2c). The effect of F_PrefT on the variable Like at the four time points was fixed to 1, as well as the effect of F_Like on Like1 and the effect of F_Dislike on Dislike1, with the aim of facilitating the metrics of the latent variables and the convergence of the model (Figures 1 and 2a). We hypothesized that the effect of each F_PrefT on each variable DislikeT would be negative and would have the same value at the four time points ("- $b$ " effect). It was assumed that the effects of F_Like on Like2, Like3, and Like4 are equal ("c" values); similarly, the effects of F_Dislike on Dislike2, Dislike3, and Dislike4 would have the same value, " $d$ ", in Figures 1 and 2c. It was assumed that " $c$ " would be greater than " $\mathrm{d}$ ".

In the case of academic results, the indicators are the marks in mathematics (Mats) and the marks in Spanish language (Lang) in each time point, which are influenced by the temporal factors Academic performance $\left(F_{-} A P T\right)$ in each of the four measurement time points (Figures 1 and $2 \mathrm{~b}$ ), and the factors that represent the indicators Performance in mathematics (F_Mats) and Performance in Spanish language (F_Lang), assuming positive covariance between both factors (parameter " $k$ " in Figures 1 and $2 d$ ). The effect of each $F \_A P T$ on each of the MatsT variables at the four time points was fixed to 1, as well as the effect of $F \_M a t s$ on Mats1 and the effect of F_Lang on Lang1. It was assumed that the loadings of each F_APT on each coetaneous LangT would be equal ( $F \_A P 1$ on Lang1, . . , to F_AP4 on Lang4), (" $h$ " effects). The effects of $F_{-}$Mats on Mats2, Mats3, and Mats4 were expected to be equal (" $i$ " parameters), and that the effects of F_Lang on Lang2, Lang3, and Lang4 would also be equal (" $j$ " effects), with no difference between the " $i$ " and " $j$ " effects.

Lastly, in the structural model of temporal effects, it was assumed that there would be an immediate AR effect of any F_PrefT on F_PrefT at the next time point, that is, an effect of F_Pref1 on F_Pref2, . . , to F_Pref3 on F_Pref4, with equal " $a$ " magnitudes. The same would be for $F \_A P T$, with the effects of $F \_A P 1$ on $F \_A P 2, \ldots$, to $F \_A P 3$ on $F \_A P 4$ being equal to " $g$ ". Regarding the effects of social relationships on academic performance (Figures 1 and 2e), each F_PrefT in each time point influences $F \_A P T$ at the same time point (F_Pref1 in $F \_A P 1, \ldots$, F_Pref4 in F_AP4); it is proposed that the effect is the same in all time points ("l" effects).

With the aim of providing further evidence that supports or refutes some of the hypotheses of M1, it was decided to use a series of variants of this model, in order to test alternative hypotheses and thus either corroborate or reject the proposed model with respect to other alternative models. Specifically, we tested models on the intercepts (proportional or equivalent to the means), the invariances of the factor loadings, the positive bias of the likes in F_PrefT and F_Like, and the negative asymmetry of Dislike and F_Dislike on academic performance, as well as the multilevel effects on the obtained results.

\section{Results}

The data analyses were conducted with IBM SPSS Statistics for Windows, Version 26.0 [58] for the descriptive analyses and with EQS 6.4 Structural Equation Modeling Software [59] for the SEM. The means, standard deviations and Pearson's correlation coefficients $(r)$ between the observable variables for the 169 participants who completed all the data are shown in Table 1, where we included dotted lines to indicate the separation between variables in different measurement time points, i.e., from $T 1$ to T4. 
Table 1. Correlations, means and standard deviations of the variables with the subjects participating in the longitudinal study ( $\mathrm{N}=169$ ).

\begin{tabular}{|c|c|c|c|c|c|c|c|c|c|c|c|c|c|c|c|c|}
\hline & Like1 & Dislike1 & Mats1 & Lang1 & Like2 & Dislike2 & Mats2 & Lang2 & Like3 & Dislike3 & Mats3 & Lang3 & Like4 & Dislike4 & MatsT4 & Lang4 \\
\hline Like1 & 1 & & & & & & & & & & & & & & & \\
\hline Dislike1 & $-0.406^{* * *}$ & 1 & & & & & & & & & & & & & & \\
\hline Mats1 & $0.333^{* * *}$ & $-0.271^{* * *}$ & 1 & & & & & & & & & & & & & \\
\hline Lang1 & $0.313^{* * *}$ & $-0.377^{* * *}$ & $0.767^{* * *}$ & 1 & & & & & & & & & & & & \\
\hline Dislike2 & $-0.268^{* * *}$ & $0.592 * * *$ & $-0.280 * * *$ & $-0.296^{* * *}$ & -0.391 *** & 1 & & & & & & & & & & \\
\hline Mats2 & $0.268^{* * *}$ & $-0.256^{* *}$ & $0.658^{* * *}$ & $0.530 * * *$ & $0.257 * *$ & $-0.263^{* *}$ & 1 & & & & & & & & & \\
\hline Lang2 & $0.346^{* * *}$ & $-0.412^{* * *}$ & $0.611^{* * *}$ & $0.681 * * *$ & $0.292 * * *$ & $-0.350 * * *$ & $0.712^{* * *}$ & 1 & & & & & & & & \\
\hline Like3 & $0.521^{* * *}$ & $-0.210^{* *}$ & $0.300 * *$ & $0.279 * * *$ & $0.563^{* * *}$ & $-0.320 * * *$ & $0.286^{* * *}$ & $0.309 * * *$ & 1 & & & & & & & \\
\hline Dislike3 & $-0.166 *$ & $0.527 * * *$ & $-0.154^{*}$ & $-0.177^{*}$ & $-0.173 *$ & $0.615^{* * *}$ & $-0.217^{* *}$ & $-0.283 * * *$ & $-0.288^{* * *}$ & 1 & & & & & & \\
\hline Mats3 & $0.186^{*}$ & $-0.255^{* *}$ & $0.582 * * *$ & $0.514^{* * *}$ & 0.127 & -0.257 ** & $0.559^{* * *}$ & $0.535^{* * *}$ & 0.223 ** & $-0.301^{* * *}$ & 1 & & & & & \\
\hline Like4 & $0.450^{* * *}$ & -0.142 & $0.236^{* *}$ & $0.167 *$ & $0.469^{* * *}$ & $-0.282^{* * *}$ & $0.321^{* * *}$ & $0.262^{* *}$ & $0.590^{* * *}$ & $-0.226^{* *}$ & 0.110 & 0.091 & 1 & & & \\
\hline Dislike4 & $-0.209^{* *}$ & $0.425^{* * *}$ & $-0.203^{* *}$ & $-0.190 *$ & $-0.274^{* * *}$ & $0.568^{* * *}$ & -0.188 * & -0.240 ** & $-0.345^{* * *}$ & $0.488^{* * *}$ & $-0.280 * * *$ & $-0.315^{* * *}$ & $-0.355^{* * *}$ & 1 & & \\
\hline Mats4 & $0.223 * *$ & $-0.186^{*}$ & $0.435^{* * *}$ & $0.322 * * *$ & 0.138 & $-0.205^{* *}$ & $0.508^{* * *}$ & $0.401 * * *$ & $0.254^{* *}$ & $-0.255^{* *}$ & $0.603^{* * *}$ & $0.447^{* * *}$ & 0.119 & $-0.287^{* * *}$ & 1 & \\
\hline Lang4 & $0.228^{* *}$ & $-0.344^{* * *}$ & $0.385^{* * *}$ & $0.474^{* * *}$ & $0.168 *$ & $-0.328^{* * *}$ & $0.421^{* * *}$ & $0.493^{* * *}$ & $0.270^{* * *}$ & $-0.317^{* * *}$ & $0.505^{* * *}$ & $0.658^{* * *}$ & $0.173 *$ & $-0.398^{* * *}$ & $0.709^{* * *}$ & 1 \\
\hline Mean & 27.201 & 15.556 & 3.858 & 3.876 & 27.290 & 11.935 & 3.769 & 3.793 & 24.669 & 6.882 & 4.077 & 4.213 & 29.621 & 8.254 & 3.893 & 4.053 \\
\hline$S D$ & 13.255 & 14.747 & 1.002 & 1.030 & 14.128 & 11.644 & 1.069 & 1.040 & 12.694 & 9.762 & 0.906 & 0.901 & 17.887 & 11.096 & 1.018 & 0.915 \\
\hline
\end{tabular}

${ }^{*} p<0.05 .{ }^{* *} p<0.01 .{ }^{* * *} p<0.001$. 
To study the $r$ differences, we used the calculator developed by Lee and Preacher [60] according to the procedure of Steiger [61,62]. For the qualitative classification of the size of the correlations, we followed the guidelines of Rowntree, Chiappa, and Vasco Montoya [63], where $r$ values are null/very small, small, moderate, high and very high/perfect at $0-0.19$, $0.20-0.39,0.40-0.59,0.60-0.79$, and $\geq 0.80$, respectively.

To study the goodness of fit of each SEM model, the following criteria were used [54,64]: (1) The Satorra-Bentler Robust Chi square $\left(\chi^{2} S B\right)$ should have a $p>0.05$, although, since it depends on the sample size, the Relative Chi-square $\left(\chi^{2} \mathrm{SB} / \mathrm{df}\right)$ was also used (df: Degrees of freedom), which should be smaller than 2; (2) the Bentler-Bonnet Nonnormed Fit Index (NNFI), the Comparative Fit Index (CFI), the Bollen Fit Index (BFI), and the McDonald Fit Index $(M F I)$ were used, and they would be between 0.85 and 0.90 to be considered poor, between 0.90 and 0.95 to be acceptable, between 0.95 and 0.99 to be very good, and $>0.99$ to be outstanding; and (3) the value of the Root Mean Square Error of Approximation (RMSEA) should be between 0.10 and 0.08 to be considered a poor fit, between 0.08 and 0.05 to be an acceptable fit, between 0.05 and 0.02 to be a good fit, and $<0.02$ to be considered a great fit. Due to the absence of multivariate normality in the variables (Normalized Estimate Multivariate Kurtosis $=16.482)$, it was decided to use the Satorra-Bentler robust estimation $[59,65]$. To compare the degree of fit between two models, the Akaike Information Criterion (AIC) was used. AIC is a criterion of relative comparison between two models, thus the lower its value, the better its relative fit. For the comparison of two models that contain the same data (regardless of whether these are nested or not) we used the Burnham, Anderson and Huyvaert [66] criterion, which establishes that, if $\Delta_{\mathrm{i}(A I C)}=A I C_{\mathrm{i}}-A I C_{\min }$, when $\Delta_{\mathrm{i}(A I C)}>7$, then the model with the highest value is not supported.

Table 2 shows the set fit indices of M1 (specified in Figure 1) and of the other models. Table 2 demonstrates that the set fit indicators of M1 are good, thus we accepted M1 as a good model of fit for the obtained data. Figure 3 shows the results obtained in M1 with the coefficients in direct scores. As can be observed in Figure 3, all the effects are significant, except that of the covariance between the factors Acceptance (F_Like) and Rejection (F_Dislike) (" $-e$ " effect in Figure 1, $-7.188 ; r=-0.158)$; although its absolute value was very high, it was little stable between participants, as is shown in its robust standard error $(S E)$, which is $13.118(t=-0.548, p=0.596)$. Another non-significant result was that of the variance of F_Dislike, which was $29.022(t=1.101, p=0.296)$, suggesting the low stability of this factor between participants, despite the fact that all its factor loadings are significant. Table 3 shows that all the means of each observable variable and of each factor are significantly different from zero. 
Table 2. Global fit results of analyzed models.

\begin{tabular}{|c|c|c|c|c|c|c|c|c|c|}
\hline Model Description & $\chi^{2} S B(d f)$ & $P\left(\chi^{2}\right)$ & $x^{2} / \mathrm{df}$ & NNFI & CFI & BFI & MFI & RMSEA & AIC \\
\hline M1. Figure 1 & $145.96(97)$ & $<0.001$ & 1.50 & 0.937 & 0.949 & 0.950 & 0.865 & 0.055 & -48.04 \\
\hline $\begin{array}{l}\text { M2. As M1, without " } a \text { ", means of } L i k e T \text { and DislikeT equal to zero, and with free factor means } \\
\text { of } F \text { PrefT }\end{array}$ & $394.13(110)$ & $<0.001$ & 3.58 & 0.781 & 0.821 & 0.825 & 0.601 & 0.102 & 174.13 \\
\hline M3. As M2, with equal factor means of $F_{-}$Pref $T$ & 421.38 (113) & $<0.001$ & 3.73 & 0.769 & 0.811 & 0.815 & 0.584 & 0.105 & 195.38 \\
\hline M5. As M4, with equal factor means of $F_{-} A P T$ & $396.04(111)$ & $<0.001$ & 3.57 & 0.778 & 0.815 & 0.819 & 0.591 & 0.103 & 174.05 \\
\hline M6. As M1, without " $l$ " effects & $183.20(98)$ & $<0.001$ & 1.87 & 0.892 & 0.912 & 0.913 & 0.777 & 0.072 & -12.80 \\
\hline M7. As M1, without " $l$ " effects, adding " $a$ " = " $g$ " effects & $185.28(99)$ & $<0.001$ & 1.87 & 0.891 & 0.910 & 0.912 & 0.775 & 0.072 & -12.72 \\
\hline M8. As M1, with $b_{0(\text { Mats } 1)}=\ldots=b_{0(\text { Mats } 4)}$ & $172.30(100)$ & $<0.001$ & 1.72 & 0.927 & 0.942 & 0.944 & 0.846 & 0.059 & -27.70 \\
\hline M9. As M1, with $b_{0(\text { Lang } 1)}=\ldots=b_{0(\text { Lang })}$ & $245.27(100)$ & $<0.001$ & 2.45 & 0.864 & 0.893 & 0.896 & 0.730 & 0.081 & 45.27 \\
\hline M10. As M1, with $b_{0(\text { Mats } 1)}=\ldots=b_{0(\text { Mats } 4)}$ and with $b_{0(\text { Lang } 1)}=\ldots=b_{0(\text { Lang } 4)}$ & $222.42(103)$ & $<0.001$ & 2.16 & 0.903 & 0.926 & 0.928 & 0.799 & 0.068 & 16.41 \\
\hline M12. Changing the direction of " $l$ " in Figure 1 & $156.14(97)$ & $<0.001$ & 1.61 & 0.924 & 0.939 & 0.940 & 0.839 & 0.060 & -37.85 \\
\hline M13. Reciprocal effects between temporal factors & $225.31(93)$ & $<0.001$ & 2.42 & 0.823 & 0.863 & 0.866 & 0.676 & 0.092 & 39.31 \\
\hline M14. As M1, with $b_{0(L i k e 1)}=\ldots=b_{0(\text { Likee })}$ & $166.08(100)$ & $<0.001$ & 1.66 & 0.932 & 0.947 & 0.948 & 0.857 & 0.057 & -33.91 \\
\hline M15. As M1, with $b_{0(\text { Dislike1 })}=\ldots=b_{0(\text { Dislike4) }}$ & $226.68(100)$ & $<0.001$ & 2.26 & 0.918 & 0.936 & 0.937 & 0.819 & 0.064 & 26.68 \\
\hline M16. As M1, constraining $\mathrm{M}($ Like1 $)=\mathrm{M}($ Dislike1); $\ldots ; \mathrm{M}($ Like4 $)=\mathrm{M}($ Dislike4) & $295.74(101)$ & $<0.001$ & 2.93 & 0.912 & 0.932 & 0.933 & 0.714 & 0.084 & 93.74 \\
\hline M17. As $\mathrm{M} 1$, with $\mathrm{M}($ Like1 1$)=\ldots=\mathrm{M}($ Like4 $)$, and $\mathrm{M}($ Dislike1 $)=\ldots=\mathrm{M}$ (Dislike4) & $261.67(102)$ & $<0.001$ & 2.57 & 0.826 & 0.865 & 0.868 & 0.593 & 0.104 & 261.67 \\
\hline M18. As M1, with "c" = "d" effects & $146.23(98)$ & $<0.001$ & 1.49 & 0.939 & 0.950 & 0.951 & 0.867 & 0.054 & -49.77 \\
\hline M19. Figure 4 (as Figure 1 , removing the " $l$ " effects and adding the " $m$ " and " $n$ " effects) & $181.73(96)$ & $<0.001$ & 1.89 & 0.889 & 0.911 & 0.913 & 0.776 & 0.073 & -10.27 \\
\hline $\begin{array}{l}\text { M20. As M1, removing the "l" effects, adding } F_{-} L i k e \text { on } F_{-} \text {Mats and } F_{-} L a n g \text { (" } q \text { " effects), and } \\
F_{-} \text {Dislike on } F_{-} \text {Mats and } F_{-} L a n g \text { (" } r \text { " effects) }\end{array}$ & $163.31(97)$ & $<0.001$ & 1.68 & 0.915 & 0.931 & 0.933 & 0.822 & 0.064 & -30.69 \\
\hline $\begin{array}{l}\text { M21. As M1, removing the "l" effects, adding LikeT on MatsT and LangT (" } s \text { " effects), and } \\
\text { DislikeT on MatsT and LangT (" } u \text { " effects) }\end{array}$ & $199.65(96)$ & $<0.001$ & 2.08 & 0.865 & 0.892 & 0.895 & 0.736 & 0.080 & 7.65 \\
\hline
\end{tabular}

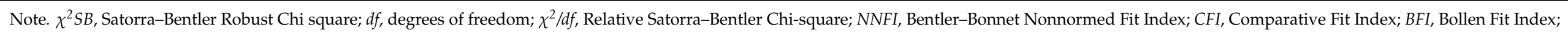
$M F I$, McDonald Fit Index; RMSEA, Root Mean Square Error of Approximation; AIC, Akaike Information Criterion. 


\subsection{Objective 1a: The Evolution of Social Relationships among Peers}

Regarding the factorial invariance of each preferences factor (F_PrefT), this is always constituted by the variables LikeT and DislikeT, thus the principle of "configural factorial invariance" is always met; moreover, the loadings are always the same, being equal to 1 in each LikeT and equal to -1.405 in each DislikeT, thereby confirming the "weak invariance" of F_PrefT. To verify the "strong factorial invariance" of F_PrefT, with the aim of determining whether the factorial means are the same, we calculated M2 (Tables 2 and 3), which is the same as M1, although, in order to equalize the conditions of the F_PrefT factors (to prevent the factors from obtaining effects of other factors or variables with different means), we removed the " $a$ " effects, zeroed the means of LikeT and DislikeT, and left the factorial means of F_PrefT free, obtaining $A I C(\mathrm{M} 2)=174.13$. However, $\mathrm{M} 2$ can be used as a reference to verify the strong factorial invariance. After equalizing the factorial means $\left(M\left(F_{-}\right.\right.$Pref 1$)=\ldots=M\left(F_{-}\right.$Pref4 $\left.)\right)$in $\mathrm{M} 3(A I C=195.38)$, its comparison to $\mathrm{M} 2$ produced $\Delta_{\mathrm{i}(A I C)}(\mathrm{M} 3-\mathrm{M} 2)=195.38-174.13=21.25$, which is a value of $\Delta \mathrm{i}\left({ }_{A I C}\right)$ higher than 7 , thus the means of $F_{-}$PrefT are different from each other and there is no strong factorial invariance of $F_{-} P r e f T$. This mean comparison procedure in SEM is equivalent to a RANOVA (analysis of variance with repeated measures). The range of $M\left(F_{-}\right.$PrefT $)$in M2 goes from 25.401 at $T 2$ to 28.194 at $T 1$ (Table 3). Considering that the $S E$ of $M\left(F_{-}\right.$Pref $\left.T\right)=0.869$, the differences between two factorial means are statistically different $(\alpha=0.05)$ from a difference between them greater than $1.703\left(=1.96^{*} 0.869\right)$, thus $M\left(F_{-}\right.$Pref 2$)<$ $M\left(F_{-}\right.$Pref 1$)$ and $M\left(F_{-}\right.$Pref 4$)<M\left(F_{-}\right.$Pref1 $)$, and the other contrasts are not different from each other (Table 3).

With respect to the AR effects of each F_PrefT, these were significant, positive, lower than 1 and equal in all transitions (" $a$ " $=0.681$, in Figure 3 ); this is very important, since it is an AR process, which depends on previous moments. Thus, the preferences expected at $T 4$, depend on T3, and these depend on T2, which, in turn, depend on T1 (see Appendix A). The effect of the independent variable $F_{-}$Pref1 in our sample is long lasting and significant along time (verified through the total effects of the system), influencing F_Pref2, F_Pref3 and their corresponding observable variables, up to $F_{-}$Pref4 (effect $=0.316, t=7.81, p<0.001$ ) and its observable variables.

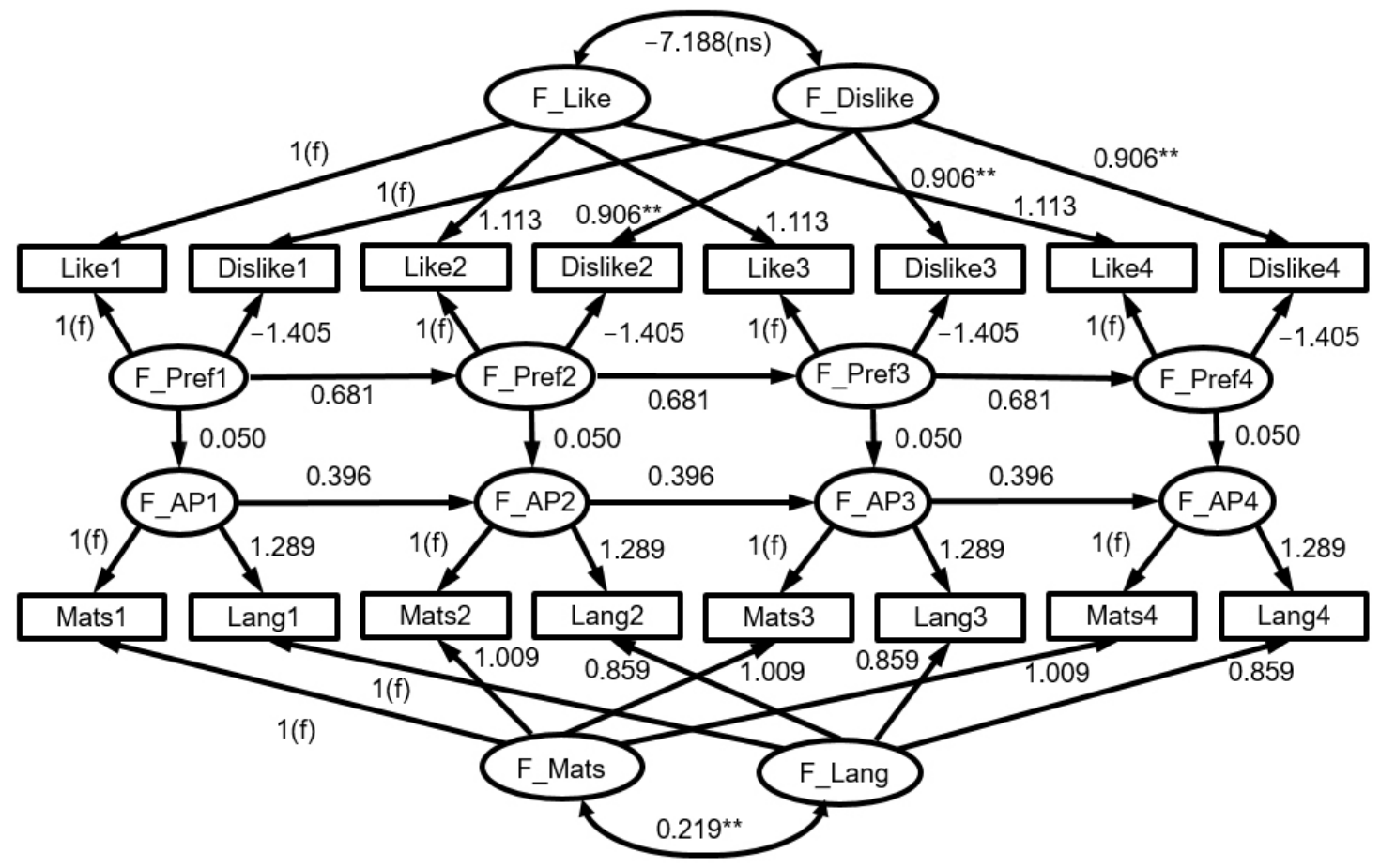

Figure 3. Representation of the results obtained with the model hypothesized in Figure 1. Notes. Effects with $1(\mathrm{f})$ are values fixed to 1. ns: Non-significant effect. ${ }^{* *} p<0.010$. All the other effects obtained $p<0.001$. 
Table 3. Means of the variables and means of the factors in the models. The means are equivalent to the intercepts.

\begin{tabular}{|c|c|c|c|c|c|}
\hline \multirow{2}{*}{$\begin{array}{c}\text { Models } \\
\text { M1 }\end{array}$} & \multicolumn{4}{|c|}{ Variables } & \multirow[t]{2}{*}{ Mean Differences } \\
\hline & Like1 & Like2 & Like3 & Like4 & \\
\hline \multirow[t]{2}{*}{ Means } & 27.201 & 27.290 & 24.669 & 29.621 & Yes (M14-M1) \\
\hline & Dislike1 & Dislike2 & Dislike3 & Dislike4 & \\
\hline \multirow[t]{2}{*}{ Means } & 15.556 & 11.935 & 6.882 & 8.254 & Yes (M15-M1) \\
\hline & Mats1 & Mats2 & Mats3 & Mats4 & \\
\hline \multirow[t]{2}{*}{ Means } & 3.858 & 3.769 & 4.077 & 3.893 & Yes (M8-M1) \\
\hline & Lang1 & Lang2 & Lang3 & Lang4 & \\
\hline Means & 3.876 & 3.793 & 4.213 & 4.053 & Yes (M9-M1) \\
\hline M2 & F_Pref1 & F_Pref2 & F_Pref3 & F_Pref4 & \\
\hline Factor Means & 28.194 & 25.401 & 26.987 & 26.178 & Yes (M3-M2) \\
\hline M4 & F_AP1 & $F \_A P 2$ & F_AP3 & F_AP4 & \\
\hline Factor Means & 3.823 & 3.733 & 4.106 & 3.946 & Yes (M5-M4) \\
\hline
\end{tabular}

Note. All values are significantly different from zero, with $p<0.001$.

\subsection{Objective 1b: The Evolution of Academic Performance}

To determine the factorial invariance of each Academic performance factor $\left(F_{-} A P T\right)$, it was observed that the loadings are always the same (Figure 3), being equal to 1 in each MatsT (previously fixed value) and 1.289 in each LangT, confirming the "weak invariance" of $F \_A P T$. To verify the strong factorial invariance of $F \_A P T$, we calculated M4 (Tables 2 and 3), which is the same as M1, although without the " $l$ ", " $a$ ", and " $g$ " effects, and with the factorial means of $F_{-} A P T$ free, which served as reference to compare it with that of the equal means, producing $A I C(\mathrm{M} 4)=116.70$. M5 was estimated, which is the same as M4, although with equal factorial means, $M\left(F \_A P 1\right)=\ldots=M\left(F \_A P 4\right)$, producing $A I C(\mathrm{M} 5)=174.05$, which, compared with M4, produced $\Delta \mathrm{i}_{(A I C)}(\mathrm{M} 5-\mathrm{M} 4)=174.05-116.70=57.35$, thus the means of $F \_A P T$ are different from each other, and there is no strong factorial invariance of $F \_A P T$. The range of $M\left(F \_A P T\right)$ (Table 3 ) goes from 3.733 at $T 2$ to 4.106 at T3. Since $S E\left[M\left(F \_A P T\right)\right]=0.062$, the differences between two means would be significant when their value is higher than $0.122\left(=1.96^{*} 0.062\right)$; therefore, all the mean differences are significant, except $M\left(F \_A P 1\right)=M\left(F \_A P 2\right)$, see Table 3 .

The effects between the temporal factors of academic performance $\left(F \_A P T, " g\right.$ " $\left.=0.396\right)$ are positive, lower than 1 and equal at all-time points, which is very important, since this is an AR process (see Appendix A). In our sample, the effect of $F \_A P 1$, as a variable independent from the rest of the $F \_A P T$, MatsT, and LangT, is also long lasting along time, being significant up to F_AP3, Mats3, and Lang3, as well as on variables of T2.

With the aim of comparing the AR effects in social relationships and in academic performance, we tested whether the " $a$ " effects (AR effects of $F \_P r e f T$ ) and " $g$ " effects (AR effects of $F_{-} A P T$ ) are equal (Figures 1 and 3). To this end, both factors must be under the same conditions, although $F_{-}$PrefT is a function of immediately previous values, and $F_{-} A P T$ is a function of immediately previous values of $F_{-} A P T$ plus the value of $F \_P r e f T$ at the same time point. To compare such AR effects, we used a model in which the " $l$ " effects are removed, thus the two temporal factors F_PrefT and F_APT only receive AR effects of their same factor (M6); then, it was compared with M7, which is the same as M6 (without " $l$ " effect), although equalizing the " $a$ " and " $g$ " effects. The results of $A I C(\mathrm{M} 6)=-12.80$ and $A I C(\mathrm{M} 7)=-12.72$, produced $\Delta_{\mathrm{i}(A I C)}(\mathrm{M} 7-\mathrm{M} 6)=-12.72-(-12.80)=0.08$ when compared, thus both models are practically equivalent. We selected the simplest of these two models, that is, the one with the largest number of degrees of freedom: M7 $\left(" a "="{ }^{\prime \prime} g^{\prime \prime}=0.481\right.$, $t=3.47, p<0.001)$. To sum up, under similar conditions, i.e., if the " $l$ " effect of $F \_P r e f T$ toward each $F \_A Q T$ did not exist, the AR effects would be similar in both temporal factors.

Regarding academic performance in specific subjects, Table 3 shows that the intercepts of each observable variable coincide with their corresponding mean in Table 1 (see Appendix B for a brief demonstration). Next, we verified whether the means of each value of MatsT are different from each other; in SEM, it is easy to make this com- 
parison, by equalizing the intercepts of each MatsT $\left(b_{0 \text { (Mats1) }}=\ldots=b_{0 \text { (Mats } 4)}\right)$ (see M8 in Table 2). In M8, all the indicators are worse than in M1; $A I C(\mathrm{M} 8)=-27.70$, when comparing this model with $\mathrm{M} 1\left(\Delta_{\mathrm{i}(A I C)}(\mathrm{M} 8-\mathrm{M} 1)=-27.70-(-48.04)=20.34\right)$, it was observed to be higher than 7, thus we accepted that the means of MatsT are not equal (there is at least one of them that differs from another). The intercepts of Mats have a range between 3.769 at $T 2$ and 4.077 at $T 3$. Considering $S E=0.061$ for the equality of means, from a mean difference of $0.120\left(=1.96^{*} 0.061\right)$, the differences would be significant if they involve T4 and T3: $M($ Mat2 $)=M($ Mat1 $)<M($ Mat4 $)<M($ Mat3 $)$, see Table 3.

With respect to academic performance in language $(\operatorname{Lang} T)$, to verify whether the means of LangT are different from each other, we tested M9 (Table 2), which is the same

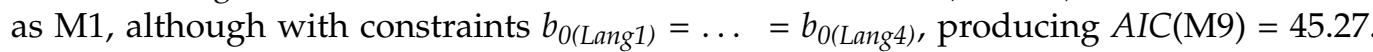
Compared to $\mathrm{M} 1\left(\Delta_{\mathrm{i}(A I C)}(\mathrm{M} 9-\mathrm{M} 1)=45.27-(-48.04)=93.31\right)$, the difference between these two models is considerable, in favor of M1, thus we reject the equality of $M(\operatorname{Lang} T)$. Table 3 shows that the means range between 3.793 (T2) and 4.213 (T3). In M9, the SE of the marks in LangT is 0.059 , thus the differences greater than $0.116\left(=1.96^{*} 0.059\right)$ would be significant, with no differences between T1 and T2; however, there would be differences between these two and the others and between T3 and T4: $M($ Lang1 $)=M(\operatorname{Lang} 2)<M($ Lang4 $)<M(L a n g 3)$.

We also verified whether the means of MatsT are different from those of LangT, since the marks in Lang are always greater than those in Mats. To this end, we used M10 as reference, where $b_{0 \text { (Mats } 1)}=\ldots=b_{0(\text { Mats } 4)}$ and $b_{0(\text { Lang } 1)}=\ldots=b_{0(\text { Lang })}$. This model, with AIC $(\mathrm{M} 10)=16.41$, is considerably worse than M1 (Table 2), and showed that the means of MatsT and those of LangT differ internally, with M1 being better (independent means). We calculated M11 with all the means equalized, $b_{0 \text { (Mats } 1)}=\ldots=b_{0 \text { (Mats } 4)}=b_{0(\text { Lang1 })}=\ldots$ $=b_{0(\text { Lang } 4)}$, obtaining $A I C(\mathrm{M} 11)=3.19$, with $\Delta_{\mathrm{i}(A I C)}(\mathrm{M} 11-\mathrm{M} 1)=16.41-(-48.04)=64.45$, thus M1, with independent means, is better than the model of equal means for MatsT and LangT.

The correlations between the empirical variables are shown in Table 1. The correlations between marks in mathematics in different time points are all significant, with high values at up to intervals of 2 years of separation and moderate values at 3, 4 and 5 years (specifically, $r=0.65$ in an interval of one year, between $r=0.56$ and $r=0.60$ with an interval of 2 years, $r=0.58$ at 3 years, $r=0.51$ at 4 years and $r=0.44$ at 5 years), with the differences of stability being significant only when the interval is 4-5 years. The correlations between the marks in language are all significant, from high at 3 years to moderate even at 5 years (specifically, $r=0.68$ in an interval of one year, between $r=0.66$ and $r=0.70$ at 2 years, $r=0.65$ at three years, $r=0.49$ at four years and $r=0.47$ at five years), observing significant differences only when the interval is 4 or more years. Within the same time interval, there are no differences in the stability of Mats or Lang, except in T2-T3.

Figure 3 shows the loadings of the factors $F_{-}$Mats and $F_{-} L a n g$ on their respective variables along time, which are significant (" $i$ " effects $=1.009, p<0.001$; " $j$ " effects $=0.859$, $p<0.001)$. The variances of the factors are significant, thus F_Mats and F_Lang are well defined by their corresponding variables.

To verify the association between the academic performance in mathematics and the academic performance in language, we calculated the covariance between $F \_$Mats and F_Lang, and compared the correlations between Mats and Lang. The covariance between $F \_$Mats and F_Lang is positive and significant $(.219, t=2.95, p<0.01 ; r=0.681)$. The correlations between MatsT and LangT at the same time point are always positive, high and significant $(p<0.001)$.

\subsection{Objective 2: The Effects of Social Relationships on Academic Performance}

According to M1 (Figure 3), it is observed that the effect of the factor Preferences (F_PrefT) on the factor Academic performance $\left(F \_A P T\right)$ is positive, significant and equal in all four time points (" $l$ " $=0.050, p \leq 0.001)$. We verified the total effects of F_Pref1 on $F \_A P T$, confirming that the influence of $F \_P r e f 1$ is significant up to F_AP4 (total ef- 
fect $=0.033, p=<0.001$ ), also reaching Mats4 (total effect $=0.033, p=<0.001$ ) and Lang4 (total effect $=0.043, p=<0.001$ ).

With the aim of determining whether the " $l$ " effect works in the opposite direction, that is, whether the factor Academic performance $\left(F_{-} A P T\right)$ influences the factor Preferences in each time point, we calculated M12 (Table 2) reversing the direction of the "l" effects of Figure 1, observing that the model fits well, although the results are worse than those obtained in M1, with $\operatorname{AIC}(\mathrm{M} 12)=-37.85, \Delta_{\mathrm{i}(A I C)}(\mathrm{M} 12-\mathrm{M} 1)=-37.85-(-48.04)=10.19$, thus M1 is better than M12; moreover, in M12, neither the " $i$ " effects nor the " $a$ " effects are significant. Likewise, there were simultaneous reciprocal effects between both temporal factors, that is, from F_PrefT to $F \_A P T$ and vice versa, for equal values of $\mathrm{T}$ (M13 in Table 2); however, the model does not fit, all the set indicators are worse $(A I C(\mathrm{M} 13)=39.31)$, and there are non-significant effects. Of the three models, M1 is the one that responds to the hypothesis and best fits the data.

\subsection{Objective 3: The Positive Bias and Negative Asymmetry of Social Relationships}

We begin this section analyzing the trajectory of the Likes and Dislikes and their stability. Firstly, we verified whether the means of each value of $L i k e T$ differ from each other, equalizing in M14 the intercepts each LikeT $\left(b_{0(\text { Like } 1)}=\ldots=b_{0(\text { Like })}\right)$. In M14 (Table 2), all the indicators are worse than in M1 M1; AIC(M14) = 33.91, and, when comparing this model with M1, $\Delta_{\mathrm{i}(\text { AIC })}(\mathrm{M} 14-\mathrm{M} 1)=-33.91-(-48.04)=14.13$, thus we accept that M1 is better than M14, and that the means of LikeT differ from each other. The intercepts of Like range between 24.669 at T3 and 29.621 at T4 (Table 3). With the aim of determining which means differ from each other, M14 showed that $S E[M(\operatorname{LikeT})]=0.879$, indicating that there were significant differences from 1.723 points $\operatorname{LikeT}\left(=1.96^{*} 0.879\right)$; therefore, $M($ Like3 $)<M(L i k e 1)=M(L i k e 2)<M(L i k e 4)$, see Table 3.

Similarly, we determined whether the intercepts of each DislikeT differ significantly from each other $\left(b_{0 \text { (Dislike1) }}=\ldots=b_{0 \text { (Dislike) })}\right)$. When equalizing these 4 intercepts (M15, Table 2), it was observed that all the set fit indicators were worse, and $\Delta_{\mathrm{i}(A I C)}(\mathrm{M} 15-$ M1 $)=26.68-(-48.04)=74.72$, indicating that the means differ. Table 3 shows that the intercepts of DislikeT range between 6.882 at T3 and 15.556 at T1. In M15, SE[M(DislikeT)] = 0.692, thus there is a significant difference between two means from $1.356\left(=1.96^{*} 0.692\right)$, with all differences being significant in the following order: $M($ Dislike $)<M($ Dislike 4$)<M($ Dislike $)$ $<M($ Dislike1), see Table 3.

Table 2 shows that, in M2, all the means of the factor PreferenceT are always positive and significantly different from zero, which indicates that the amounts of LikeT are significantly greater than those of DislikeT, since the latter variable has a negative sign, and loads in the factor with this sign. Indeed, in all the time points, the mean of Like is higher than that of Dislike $(p \leq 0.001)$ and the difference between them in favor of LikeT increases progressively from $T 1$ to $T 4(11.645,15.353,17.787$ and 21.367), verified in M16, constraining $M($ Like1 $)=M($ Dislike1 $) ; \ldots ; M($ Like4 $)=M($ Dislike4 $)$, with $A I C(M 16)=93.74$, that is, worse than M1, $\Delta_{\mathrm{i}(\text { AIC })}(\mathrm{M} 16-\mathrm{M} 1)=93.74-(-48.04)=141.78$. This result is reached in M17, with constraints Like1 $=$ Like2 $=\ldots=$ Like4, and Dislike1 $=\ldots=$ Dislike4, producing $\operatorname{AIC}(\mathrm{M} 17)=261.67$, thus it is also worse than M1.

With respect to the stability of positive and negative relationships, it was observed that: (a) In Figure 3, the factor F_Like and F_Dislike explain consistently and stably the variables LikeT (" $c$ " $=1.113, p \leq 0.001$ ) and DislikeT (" $d$ " $=0.906, p \leq 0.001$ ), respectively, although the variance of the factor $F_{-}$Dislike is not significant, which indicates a lack of internal consistency of this factor; and (b) all the correlations among LikeT and among DislikeT in different time points are significant. The stability of Likes is high in an interval of one year $(r=0.67)$, and remains moderate up to 5 years $(r=0.45)$, showing significant differences between a one-year interval and longer intervals. The stability of Dislikes is moderate, regardless of the period of temporal separation, being significantly lower at 5 years $(r=0.43)$. Within the same interval, Likes and Dislikes have the same stability.

Regarding the interdependence of positive and negative relationships, it was observed that: (a) The $r$ correlations between LikeT and DislikeT at the same time point (see 
Table 1) are significant, negative, and moderate, as well as equal in all time points $(r=-0.41$, $r=-0.39, r=-0.29, r=-0.36$, from $T 1$ to $T 4$, respectively); (b) the correlations between LikeT and DislikeT in different time points remain significant, except that of Dislike1 with Like4 $(r=-0.14)$, although they are small, showing few significant differences between them (only in 7 of the 65 possible comparisons); (c) the correlation, and covariance, between LikeT and DislikeT (with equality of $T$ ) is always significant and negative, thus the effects of the components of the factor F_PrefT are negative and significant in all time points on DislikeT ("-b" effects); and (d) the covariance between the factors F_Like and F_Dislike is not significant (" $e$ " $=-7.188, S E=13.118, p=0.584, \mathrm{~ns}$ ).

With respect to whether the Likes are better defined than the Dislikes, it was verified: (a) Whether the effect of F_PrefT on LikeT is higher than that on DislikeT, and (b) whether the effect of F_Like on Like is higher than that of F_Dislike on Dislike. (a) Figure 3 shows that each effect of F_PrefT on LikeT is equal to 1, whereas the effects of F_Pref on DislikeT are equal to -1.405 (" $-b$ " effect in Figures 1 and 3 ). To test the magnitude of the effects, we compared their absolute values; if the $S E$ of " $-b$ " is 0.260 , or $S E(-b)=0.260$, then the confidence interval (CI) of " $-b$ " is: $|\mathrm{CI}(-b)|=\left|-b \pm z_{\alpha}^{*} S E(-b)\right|=|-1.405 \pm 1.96 * 0.260|$, in absolute value: $|\mathrm{CI}(-b)|=|0.896<b<1.915|$. This means that the value 1 is within its confidence interval, indicating that there are no significant differences among the absolute effects of F_Pref on Likes or Dislikes in any time point T. (b) With the aim of verifying whether the " $c$ " effects (of F_Like on LikeT, with $T=2,3$ or 4) and the " $d$ " effects (of F_Dislike on DislikeT, with $T=2,3$ or 4 ) are equal (" $c$ " $=$ " $d$ "), we equalised these parameters (Table 2, M18), producing $A I C=-49.77$, which compared with M1: $\Delta_{\mathrm{i}(A I C)}(\mathrm{M} 18-\mathrm{M} 1)=$ $-49.77-(-48.04)=1.73$, not allowing us to reject the equality of effects. We accepted the original model, M1, since it is the one that responds to our hypothesis, as F_Like is better defined than F_Dislike.

Regarding the unequal effects of positive and negative relationships on academic performance in Table 1, the correlations of Like and Dislike with Mats and Lang show that: (a) The correlations of Like with Mats and with Lang are positive and small or very small, whereas those of Dislike are negative and small; (b) neither the correlations of Like nor those of Dislike are different for Mats with respect to Lang; (c) at the same time point, both the Likes and the Dislikes have small significant correlations, both with Mats and with Lang, although Dislike has a stronger association with Lang at T3 $(p=0.02)$ and at T4 $(p=0.01)$, and with Mats at T4 ( $p=0.05)$; (d) at different time points, the correlations are also significant, except 4 correlations of Like, i.e., 2 with Mats (T2-T3 and T2-T4) and another 2 with Lang (T1-T3 and T2-T3); and lastly, (e) at different time points, the associations of Like and Dislike with Mats are similar, whereas the associations of Dislike with Lang are stronger than those of Like, with the following significant correlations: Dislike1-Lang3 ( $p=0.001)$, Dislike2-Lang3 $(p=0.01)$, and Dislike2-Lang4 $(p=0.06)$.

To verify the possible greater effect of the Dislikes compared to the Likes in F_APT, model M19 was proposed (Figure 4), which is the same as M1, although without the "l" effects of the factor F_Pref on each factor F_APT (Figure 1), replacing them in Figure 4 with the effects of the factor $F \_$Like on each factor $F \_A P T$, equalizing them (" $m$ " effects), and with the effects of $F \_D i s l i k e$ on each $F \_A P T$, equalizing them (" $n$ "). The results (Table 2 ) show that $A I C(\mathrm{M} 19)=-10.27$, with $\Delta_{\mathrm{i}(A I C)}(\mathrm{M} 19-\mathrm{M} 1)=-10.27-(-48.04)=37.77$, indicating that M1 is better than M19. Moreover, paradoxical and non-significant direct effects were obtained: " $m$ " $=-0.132, S E=0.088, t=-1.492, p=0.136$; and " $n$ " $=0.019, S E=0.029$, $t=0.651, p=0.516$. Therefore, the direct effects of $F \_$Like and F_Dislike on each F_APT are not met. 


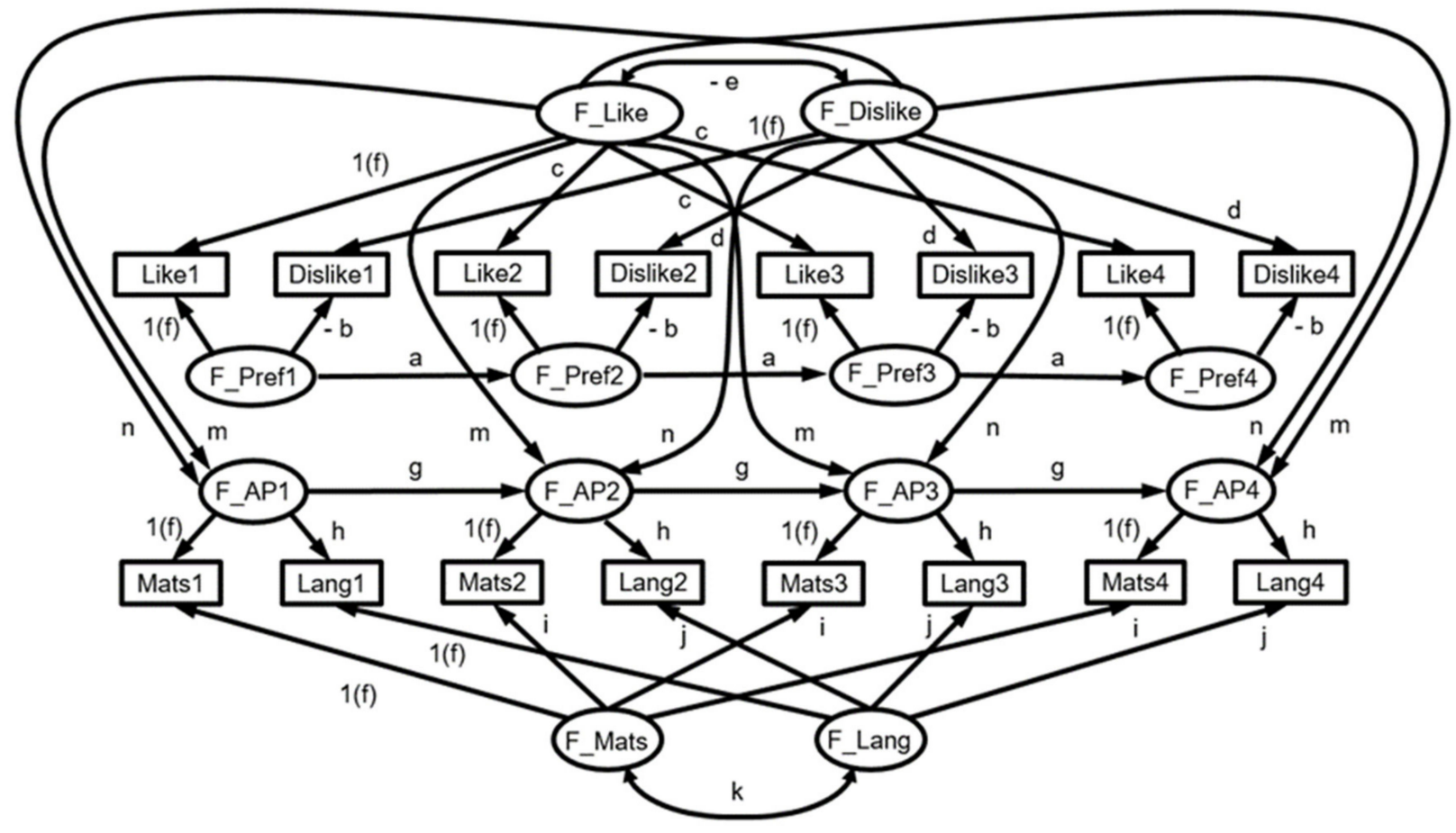

Figure 4. Representation of M19. Results of the " $m$ " and " $n$ " effects on the text.

We tested the direct effect of each factor $F_{-}$Like and $F_{-}$Dislike on the factors $F_{-}$Mats and $F \_L a n g$, removing the " $l$ " effects, equalizing the effects of $F \_L i k e$ on F_Mats and F_Lang (" $q$ " effects), and equalizing the effects of $F \_$Dislike on the factors $F \_$Mats and $F \_L a n g$ (" $r$ " effects), naming it M20. This model produced $A I C(M 20)=-30.69$, thus M1 is better than $\mathrm{M} 20, \Delta_{\mathrm{i}(A I C)}(\mathrm{M} 20-\mathrm{M} 1)=-30.69-(-48.04)=17.35 ;$ moreover, the effects of $F \_$Like on F_Mats and F_Lang were not significant ( $" q$ " $=0.044, S E(q)=0.026, t=1.700, p=0.091)$, as well as the effects of $F \_D i s l i k e$ on $F \_M a t s$ and $F \_L a n g(" r$ " $=0.017, S E(r)=0.026, t=0.669$, $p=0.504)$.

Lastly, since the theory of asymmetry considers direct values of Like and Dislike as variables, we also tested M21, which is the same as M1 (Figure 1), although without the " $l$ " effects and with the effects of LikeT on MatsT and LangT in each measurement time points, which were equal along time ("s" effects); this model also adds the effects of DislikeT on MatsT and LangT in each time point, which were equal along time (" $u$ " effects). The results in Table 2 show that $A I C(\mathrm{M} 21)=7.65$, which, compared to M1, $\Delta_{\mathrm{i}(A I C)}(\mathrm{M} 21-\mathrm{M} 1)=7.65-$ $(-48.04)=55.69$, thus M1 is better than M21. However, the effects were consistent and significant: Those of LikeT on MatsT and LangT (" $s$ " $=0.004, S E(s)=0.002, t=2.17, p=0.031$ ) and those of DislikeT on MatsT and LangT $(u=-0.013, S E(u)=0.003, t=-4.50, p<0.001)$.

\subsection{Ojective 4: The Multilevel Effect}

To verify Objective 4, we analyzed M1 with a multilevel procedure (M22), with the intercepts of the free observable variables, observing that M22 does not converge (Table 2). We also performed a multilevel analysis with the intercepts of the observable variables Like (M23), Dislike (M24), Mats (M25) and Lang (M26) separately, as well as of the AR " $a$ " and " $g$ " effects (M27), and of the "l" effect (M28) between factors (Figure 1). None of these model was significant, thus we did not include further information in Table 2. Therefore, we reject the multilevel hypothesis, and all the children in all classrooms follow the model specified in M1.

\section{Discussion}

This study is an important contribution to the need proposed recently by Wentzel et al. [40], i.e., the need to formulate precise theoretical models to explain the connection between social acceptance and academic performance. The model of relations proposed in 
this investigation about these two constructs proved to be solid and very stable throughout the entire period of primary school. All the effects hypothesized in the model are repeated and equal in all time points, with the proposed model showing better fit than the other alternative models tested. Moreover, the adaptation of this model to the data is strengthened by the fact that it can be generalized to all classrooms. With no intention of being excessively thorough, we highlight the main findings regarding the different objectives of the study.

\subsection{Evolution and Stability of Social Relationships and Academic Performance}

The observed trends, both in social acceptance and in academic performance, have a long lasting effect, influencing from one time point to the next in the entire period of primary education (i.e., from 1st to 6th grades). That is, children with worse social status among peers or with lower academic performance at the beginning of schooling are still in a disadvantageous position at the end of primary education. This indicates that, in the absence of explicit intervention, social and academic disadvantage prevails despite schooling, with trajectories being relatively defined from the first years of primary education, which is in line with the findings of other longitudinal studies [2]. This result is a fundamental contribution of this study, since, as is later discussed in this article, it had important implications for intervention.

\subsubsection{Evolution and Stability of Academic Performance}

The marks in mathematics and those in Spanish language are well and stably explained by the factors "performance in mathematics" and "performance in language", respectively. From the analysis performed on each observable variable of academic performance (marks in mathematics and marks in language), it is deduced that, despite some small differences between these two, they work in a very similar manner: There is a strong relationship between them, similar evolution trends (slight significant fluctuations in some time points), and high and moderate-high stability in periods of 3 years and 5 years, respectively. This strong similarity and connection between performance in mathematics and performance in language is further evidence that the development of language and mathematics are mutually predicted [42].

In the global evolution of these variables, it is important to highlight two results. On the one hand, there was an increase of performance at the age of 9-10 years (T3), which is in line with the consolidation of the phase of "industriousness" or greater involvement in school work proposed by Erikson [67], with the adoption of behavioral standards valued by adults, typical of such age (Bandura, 1986, cit. in [40]), and with the establishment of the basic instrumental skills of reading, writing, and calculating. It is not surprising that, probably due to these reasons, teachers in general prefer to teach students of this age [68]. The later decrease of performance in the last year of primary education is probably related to the decrease of academic motivation in the transition from preadolescence to adolescence [69]. On the other hand, the tendency toward greater performance in language than in mathematics is coherent with the greater school failure and demotivation that are consistently found in mathematics along time [70,71].

With respect to academic performance, determined from the marks in mathematics and language, proved to be very consistent and stable. The autoregressive effects of performance by year are statistically significant, showing that the performance in a given time point depends on the performance of the previous time point. These effects are positive, significant, equal in the same intervals and long lasting, being significant from 1st to 6th grades. This means that the performance of a child with respect to that of other children remains relatively in the same position throughout primary education [42]. The slight variations between courses in the class as a whole may be related to the change of teachers, as well as to the reasons formulated in the previous paragraph. 
Therefore, we can confirm the robustness and goodness of the construct of academic performance evaluated by the teacher and the validity of unifying the performance in different subjects in a single factor [40,49].

4.1.2. Evolution and Stability of Social Acceptance: Likes, Dislikes, Social Preference, and Positive Bias

Regarding the dependence-interdependence between acceptance and rejection, we must point out that, first of all, our results are relatively paradoxical, since the covariances and correlations between likes and dislikes at each time point and at different time points are significant [72], whereas the covariance between acceptance and rejection is not significant. These data, considered as a set, indicate that, at the level of observable variables, there is moderate dependence between acceptance and rejection, whereas at the factor level (acceptance and rejection) they appear to be independent variables. However, the hypothesis of Bukowski et al. [9] about the dependence between positive and negative relationships within each year (from 1st to 6th grades) was confirmed, at least partially, although this aspect is not solved and will have to be addressed in future research. In any case, it was confirmed, on the one hand, that we must be cautious with the use of social preference as a combined measure of like and dislike and, on the other hand, these findings encourage us to advance in the simultaneous and differential study of both social experiences.

A first analysis of the social preference factor, from 1st to 6th grades, indicates that it is well configured by the like and dislike variables of different sign (positive and negative), showing stability and internal consistency. As in the case of academic performance, the autoregressive effects of preference are positive, significant, equal in the same intervals and long lasting, being significant from 1st to 6th grades, which clearly indicates that the social status of children is relatively the same throughout the entire period of primary education [33]. However, despite the stability of the construct of social preference and its strong autoregressive effect, as was described in the discussion on the dependence between acceptance and rejection in the previous paragraph, and as is shown in the analysis of its internal composition and in the analysis of the rates, trajectories and stability of the like and dislike variables presented below, the use of the preference dimension can cover up the peculiarities of acceptance and rejections experiences $[10,11]$.

Are likes better defined than dislikes by social preference? On the one hand, the answer would be negative, since we did not find significant differences between the effects of preference on like and dislike in any of the time points. However, the cumulative effect of the preferences factor on likes tends to be greater than that on dislikes; the same conclusion was drawn from the analysis of the effects of the acceptance and rejection factors on likes and dislikes, respectively. On the one hand, both likes and dislikes are well defined by their respective factors, whereas, on the other hand, the variance of the rejection factor is not significant, which indicates that this factor does not have internal consistency, probably due to the fact that the variability of dislikes is greater than that of likes. To sum up, with no intention of providing a concluding answer, it seems that likes are better defined that dislikes.

The analysis of likes and dislikes at the different time points confirms the hypothesis that these variables have different distributions and behaviors in time. Higher means and much lower variances were stably observed in the values of likes than in those of dislikes. The rate of likes remains relatively stable, despite the decrease in fourth grade, and that of dislikes clearly decreases, despite its increase in sixth grade with respect to fourth, with a progressive increase of the distance between likes and dislikes. Therefore, it is confirmed that the evolutionary trajectories of likes and dislikes are different. This differential evolution could be explained by the socialization process, where children learn that it is reprehensible to deliberately show dislike toward others [73], as well as by the acquisition of rules of politeness that encourage emphasizing positive aspects [17], thus confirming the hypothesis of positive bias. Lastly, the extension of the stability of acceptance and rejection in time also contributes to justifying the relevance of analyzing it 
separately. The progression of the children that remain in the sample at the different time points indicates a high stability of likes in periods of one year and moderate in periods of 5 years, whereas the stability of dislikes was moderate in different time points.

These results, interpreted as a whole, could support the hypothesis of positive bias [74], as it seems that the variables related to acceptance are strengthened by the fact that likes are more numerous, visible, and stable than dislikes. However, this aspect should be further explored, since an alternative hypothesis for these differences is that they are due to a more normal distribution of likes, whereas dislikes are concentrated in fewer individuals. Somehow, as is the case of aggression and bullying, rejection is a less normative adverse experience.

\subsection{Effects of Social Relationships on Academic Performance}

The results show that social relationships among peers have a significant, stable and long lasting effect on academic performance from first to sixth grades of primary education with the model showing greater fit in this direction than in the opposite direction and, in addition, greater fit than the model of bidirectional influences. Our hypothesis is confirmed, both for the means of preference and for those of likes and dislikes separately, as well as both for the global performance factor and for performance in language and mathematics. This confirms the strength of social status as a "driver" of development and the stability of its effects on performance found by Wentzel et al. [40] in their meta-analysis.

Regarding the temporal dimension, Wentzel et al. [40] found an association between acceptance and academic performance as twice as strong for students of primary education with respect to students of secondary education. Considering that being appreciated by the teacher is based, partly, on academic performance, it is reasonable to presume that younger students would also appreciate the classmates who stand out academically, whereas adolescents may prefer classmates with attitudes of academic detachment. This decrease of the effect is not observed in our model, in which the effect remains stable up to 6 th grade.

How does social status influence performance? Wentzel and Caldwell [44] proposed that the feeling of belonging and cohesion motivates participation in school activities. Belonging to a group of peers promotes and strengthens norms, values, and behaviors that facilitate academic performance [1], and acceptance from others facilitates the access to resources that promote performance, such as help received from others and shared information. Ryan and Shin [3] identified three specific mechanisms: (1) Peers as agents of socialization; (2) peers as a source of social and emotional support; and (3) peers as members of a network with hierarchies. Wentzel et al. [40] highlighted that motivation plays a mediating role in these connections between social acceptance and academic performance, since children who enjoy positive relationships may feel more committed to academic activities than those who have problems with peer relationships $[46,75]$.

The Predictive Power of Rejection: Negative Asymmetry

The results showed that both dislikes and likes have significant effects on mathematics and language, although the negative effect of dislikes is greater than the positive effect of likes, with such difference not being significant. This was also observed in the size and stability of the correlations of likes and dislikes with mathematics and language, especially those with the latter.

Why does rejection seem to have a stronger impact on performance compared to acceptance? As was proposed in the introduction, if acceptance responds to the basic need of belonging, it is logical to think that "good things in life are taken for granted" (Sears, 1983, cited in [76]), whereas not meeting this need, threatened by rejection, can cause psychological deficits and maladjustments [25]. Complementarily, rejection also increases the probability of being exposed to other rejected students, which could worsen the effects on school adjustment and performance [28]. However, there seem to be more reasons to understand the damage caused by rejection. Thus, Gerber and Wheeler [30] proposed that 
rejection is more likely to affect the need to sense control of one's life rather than one's need of belonging. Gerber and Wheeler [30] found that people react to rejection with aggressive and antisocial responses with the aim of recovering control, leading to an accumulation and chronification of adverse experiences, which could explain that the negative effects of rejection on performance are greater than the positive effects of acceptance [35].

\section{Conclusions, Future Research Lines, and Educational Implications}

\subsection{Conclusions, Limitations and Future Research Lines}

This study confirms the stability of peer relationships and academic performance throughout childhood, as well as the influence, also stable and consistent, of social relationships on performance. The model is completely stable. All the effects of the model are repeated and successively transmitted from one time point to the next. Thus, it is convenient to highlight the short-, mid-, and long-term impact of the social status of children at the beginning of primary education, and point out the failure of the education system to address the starting social and school disadvantages and disrupt negative development trajectories, thereby showing that it has not met the goals of inclusive education. This is in line with the negative results of school or migratory mobility described in the Participants section. These results encourage the study of the impact of these and other early experiences of peer relationships on academic performance and on other aspects of school and socioemotional adjustment, as well as the identification of individual cases in which it is possible to break this cycle of rejection and low performance [38], with the aim of detecting early intervention keys for the future.

This work also confirms the importance of considering acceptance and rejection (likes and dislikes) simultaneously and differentially, with two of its most important contributions being the confirmation of positive bias in social relationships, with likes being more numerous, stable and homogeneous than dislikes, and the confirmation of negative asymmetry or a greater effect of dislikes on academic performance. It is necessary to further delve into the differential nature, trajectories and effects of likes and dislikes, and clarify the complex and unresolved matter of their mutual dependence-interdependence.

This study is an important contribution to the connection between social status and performance, providing longitudinal data throughout the entire period of primary education and indicating one direction. It confirms the role of social status among peers as the origin and driving force of psychological and school adjustment. However, it is still necessary to develop new models that incorporate explanatory variables, such as motivation and participation $[29,40,45]$.

Among the limitations of this work, we have to mention some associated with sociometric measures and some related to the fact that we did not take into account the role of the family's socioeconomic background in school performance. Regarding the first point, although there is no doubt about the validity of peer nominations as a method for measuring peer relationships [52,77], additionally, these authors highlighted the importance of being precise in these measures. We made the decision to limit the likes and dislikes nominations to classmates enrolled in the same classroom as the nominating child, which was consistent with our objectives and facilitated the difficult task of obtaining longitudinal sociometric data. Yet, this makes it impossible to know the totality of acceptance and rejection relationships that each child had, including the ones s/he had with children from other classrooms of the same grade or even from different grades in the same school. In this sense, one of the limitations of this study, and at the same time future line of research, refers to conducting studies that compare both types of measures, nominations limited to classmates from the same classroom or open to children from other classrooms and grades. This could be particularly important when analyzing the relationships of the repeat students, who represent a significant portion of the subjects in the non-longitudinal group of the present study. Regarding the second limitation, it seems clear that the relationships between a student's socioeconomic background and her/his educational achievement appear to be persistent and substantial [78]. In this sense, and even though the objective 
of our study was more descriptive than explanatory, we agree with Thomson [78] in the statement that using family variables would have allowed us to better understand the transmission mechanisms by which socioeconomic background influences student attainment and peer relationships. In fact, in our study, although we found no differences in these variables between Caucasian and other minority ethnicities in the children belonging to the longitudinal sample, we did find significant differences, in almost all the variables at each time point, between the subjects belonging to the longitudinal study sample and those belonging to the non-longitudinal one, that is, in the analysis of the sample of all the students actually present at each measurement. This would support our conclusion that the school does not reverse the disadvantages originating from the socioeconomic inequalities that each child carries with her/himself to school, but rather reproduces them, and that to belong to a minority ethnic group can help to understand the negative consequences associated with student mobility and school change $[79,80]$. Indeed, in our study, the students belonging to a minority ethnic group represent almost all the students with school change, and these students with such mobility had worse academic and social results than those who remained in the same school during all primary education. Therefore, research that incorporates more family variables, such as father's and mother's educational and professional levels [78], is necessary and hopefully would provide accurate basis for inclusive educational policies.

\subsection{Educational Implications}

The tendency toward positive bias may pose a loss of opportunities to face, in a realistic manner, acceptance and rejection as two necessary and complementary experiences of our social life. It would be necessary to fight the idea of rejection as something dysfunctional, and enhance an understanding of occasional interpersonal rejection as a common experience [7]. Most people meet their need of belonging and experience acceptance from others throughout life, along with some experiences of rejection, and we seem to have enough protective mechanisms to cope with these occasional adverse experiences without great consequences in the long term $[5,25]$. From the theories of psychological risk and the theory of stress, it is proposed that what really poses a risk to development is the continuous exposure to negative experiences [31]. Therefore, in the same manner as negative emotions, rejection can also involve important adaptive functions: It warns about situations or events that have implications for social acceptance, acts as negative feedback of undesirable behaviors, motivates us to protect our relationships and the people we care about, and prepares us to repair the damage of important relationships [81].

Considering that early and coetaneous social status in the classroom proved to influence academic performance, future interventions, in addition to being focused on the improvement of performance itself, should be designed to favor relational experiences, especially the prevention of rejection and the promotion of acceptance among peers. Thus, early, sequenced, global, and ecological interventions must be carried out with the aim of ensuring the compensatory and inclusive effect of the school $[2,36]$. With respect to rejection, children must increase their comprehension of their own experiences of rejection and those of their peers, incorporate the benefits of these experiences in their social dynamics and develop mechanisms to cope with their own rejection and help their rejected classmates. This type of intervention would contribute to prevent the school failure and drop-out caused by the chronification of problematic relationships with peers $[47,82,83]$. As was stated by Jimerson et al. [2], when a path is imposed, numerous factors conspire for its continuation. It is also necessary to provide peer acceptance experiences to rejected children. Some studies show that the reactive aggressiveness of rejected children decreases when they receive small shows of acceptance from others, that rejected children engage in prosocial behaviors if they perceive possibilities of acceptance, and that they are oriented to actively search for people with whom they can establish new connections [25]. Lastly, the type of academic tasks also affects learning, behavior, acceptance and rejection. Barrera and Schuster [84] found that orientation toward learning promotes prosocial behavior and 
acceptance, whereas orientation to performance favors competitiveness and rejection. This suggests that the syllabi should guide teachers to incorporate in their daily practice the structures of cooperative learning [40,50], which enhance at the same time school learnings and the development of social skills and positive relationships.

Author Contributions: Conceptualization, F.J.G.B., V.M.T., and G.M.P.; methodology, J.F.R.R., F.J.G.B., and G.M.P.; formal analysis, J.F.R.R. and F.J.G.B.; investigation, F.J.G.B. and G.M.P.; data curation, G.M.P.; writing—original draft preparation, F.J.G.B., J.F.R.R. and V.M.T.; writing—review and editing, F.J.G.B., J.F.R.R., V.M.T. and G.M.P.; visualization, J.F.R.R. and F.J.G.B.; supervision, F.J.G.B.; funding acquisition, F.J.G.B. All authors have read and agreed to the published version of the manuscript.

Funding: This research was funded by Spanish Ministry of Economy and Competitiveness (EDU201235930) and Universitat Jaume I (UJI-B2019-29).

Institutional Review Board Statement: The study was conducted according to the guidelines of the Declaration of Helsinki, and approved by the Ethics Committee of Universitat Jaume I (PI: Francisco Juan García Bacete; date of approval: 3 July 2017).

Informed Consent Statement: Informed consent was obtained from all subjects involved in the study.

Data Availability Statement: The dataset is available at the public repository of the Universitat Jaume I (doi:http:/ / dx.doi.org/10.6035/PSI.2020.12).

Acknowledgments: Adrian Serrano Linares (translator).

Conflicts of Interest: The authors declare no conflict of interest.

\section{Appendix A}

The equation of the score of a child " $i$ " in $F_{-} \operatorname{Pref}_{i}$ (Figure 1 ) is shown to only receive an effect from its previous factor score $F_{-}$Pref3 $_{i}$ :

$$
F_{-} \text {Preft }_{i}=a \cdot F_{-} \text {Pref3 }_{i}+D_{i\left(F_{-} \text {Pref } 4\right)}
$$

where $a$ is the value of the AR coefficient, which is common to the entire sample, and $D_{i\left(F_{-} \text {Pref } 4\right)}$ is the prediction error (or disturbance) of the same child " $i$ " in factor F_Preft. To simplify the demonstration, let us suppose that we do it with predicted values at each time point and without considering the means; thus, instead of operating with the direct values, we enter the predicted values $F_{-}$Pref $4_{i}{ }^{\prime}$ and $F_{-}$Pref $3_{i}{ }^{\prime}$, therefore, the error $D_{i\left(F_{-} P r e f 4\right)}$ is equal to zero:

$$
\text { F_Pref } 4_{i}{ }^{\prime}=a \cdot F_{-} \text {Pref }_{i}{ }^{\prime},
$$

although, if we consider that in the previous time point: $F_{-} \operatorname{Pref} 3_{i}{ }^{\prime}=a \cdot F_{-} \operatorname{Pref} 2_{i}{ }^{\prime}$ :

$$
F_{-} \operatorname{Pref}_{i}{ }^{\prime}=a \cdot\left(a \cdot F_{-} \operatorname{Pref} 2_{i}{ }^{\prime}\right)=a^{2} \cdot F_{-} \operatorname{Pref} 2_{i}{ }^{\prime},
$$

and the same goes for the value $T 1$ :

$$
F_{-} \operatorname{Preft}_{i}{ }^{\prime}=a^{2} \cdot\left(a \cdot F_{-} \operatorname{Pref1}_{i}{ }^{\prime}\right)=a^{3} \cdot F_{-} \operatorname{Pref1}_{i} .
$$

That is, the value of F_Pref4 depends on previous values of the same child in factor $F_{-} P r e f T$, for any value of T. It is shown that, for values $F_{-} \operatorname{Pref1}_{i}$ we did not include the indicator of prediction (superscript quotation mark), since these are primitive values, without prediction and without prediction error. However, statistically and substantively, immediate values must exert greater influence than remote values; therefore, the value of the AR coefficient must be lower than 1 . In our case (Figure 3), we have that $F_{-}$Pref $_{i}{ }^{\prime}=0.681 \cdot F_{-}$Pref3 $_{i}{ }^{\prime}$ (applying Equation (A2)), although using Equation (A4): F_Pref4 ${ }_{i}{ }^{\prime}$

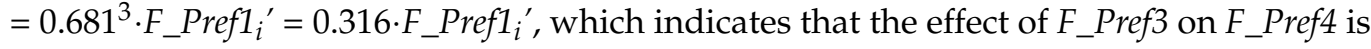
0.681 , whereas the effect of $F_{-}$Pref 2 on $F_{-}$Pref4 4 is 0.464 , and the effect of $F_{-}$Pref1 on F_Pref4 is 0.316 , which is becomes much smaller along time. In the case that the " $a$ " effect was 
greater than one, remote values of $F_{-} P r e f T$ would exert greater influence than near values, which would make no sense.

Similarly, for the variance of $F_{-}$Preft', or $\operatorname{Var}\left(F_{-}\right.$Preff' $)$, we removed the suffix " $i$ ", which indicates "individual" in Equation (A1), since the variance is a sample statistic, not an individual statistic; applying the calculation of the variance of expected values in Equation (A2):

$$
\operatorname{Var}\left(F \_P r e f 4^{\prime}\right)=\operatorname{Var}\left(a \cdot F \_P r e f 3^{\prime}\right),
$$

expanding Equation (A5), we obtain:

$$
\operatorname{Var}\left(F_{-} \operatorname{Pref4^{\prime }}\right)=a^{2} \cdot \operatorname{Var}\left(F_{-} \operatorname{Pref} 3^{\prime}\right),
$$

consequently:

$$
\left.\operatorname{Var}\left(F_{-} \operatorname{Pref} 4^{\prime}\right)=a^{2} \cdot a^{2} \cdot \operatorname{Var}\left(F_{-} \operatorname{Pref} 2^{\prime}\right)\right)=a^{4} \cdot \operatorname{Var}\left(F_{-} \operatorname{Pref} 2^{\prime}\right)=a^{6} \cdot \operatorname{Var}\left(F_{-} \operatorname{Pref1}\right),
$$

thus $\operatorname{Var}\left(F \_P r e f 4^{\prime}\right)$ is a function of the variance of previous values and of the AR term " $a$ "; if " $a$ " were greater than 1 , the value of $\operatorname{Var}\left(F_{-} \operatorname{Preff} 4^{\prime}\right)$ would be a very large number, and if the series were very large, it would tend to be 'explosive'. However, since it produced a value of 0.681 in Figure 3, then $\operatorname{Var}\left(F_{-}\right.$Preff $\left.4^{\prime}\right)=0.681^{6} \cdot \operatorname{Var}\left(F_{-}\right.$Pref1 $)=0.100 \cdot \operatorname{Var}\left(F_{-}\right.$Pref1 $)$, although, if it had produced an " $a$ " value greater than 1 (e.g., 1.319), then $\operatorname{Var}\left(F_{-}\right.$Pref4' $)=1.319^{6} \cdot \operatorname{Var}\left(F_{-}\right.$Pref1 $)=$ 5.266. $\operatorname{Var}\left(F_{-}\right.$Pref1 $)$, thus $\operatorname{Var}\left(F_{-}\right.$Pref1 $)$would exert greater influence than $\operatorname{Var}\left(F_{-} P r e f 3^{\prime}\right)$, and the farther away from the initial time point, the greater the expected variance would be and the greater the influence on remote values, which would make no sense.

\section{Appendix B}

It is easily demonstrated that the intercept of an observable variable, when influenced only by factors, is the mean of that same variable. Considering, for example, the variable Lang2 for a child, subscript " $i$ " $\left(\right.$ Lang $\left.2_{i}\right)$, in Figure 1 :

$$
\operatorname{Lang}_{i}=b_{0(\text { Lang } 2)}+h \cdot F_{-} A P 2_{i}+j \cdot F_{-} L_{\text {ang }} i+E_{i(\text { Lang } 2)},
$$

where $b_{0 \text { (Lang2) }}$ is the value of the intercept of Lang2, common to the entire sample, " $h$ " and " $j$ " are the respective coefficients of the factor scores of child " $i$ " for $F_{-} A P 2_{i}$ and $F_{-} L a n g_{i}$, respectively, and $E_{i(\operatorname{Lang} 2)}$ is the prediction error of the variable Lang2 of child " $i$ ". If we calculate expected values in Equation (A8):

$$
E\left(\text { Lang }_{i}\right)=E\left(b_{0\left(\text { Lang }_{2}\right)}+h \cdot F_{-} A P 2_{i}+j \cdot F_{-} L_{\text {ang }}+E_{i}\right) .
$$

Considering that the expected value of a variable (e.g., Lang2) is its mean, that of a constant $\left(b_{0(\text { Lang } 2)}\right)$ is the constant itself, the value of any factor ( $F \_A P 2$ and $\left.F \_L a n g\right)$ is zero, and that of any measurement error $(E)$ is also zero, Equation (A9) would be:

$$
M\left(\text { Lang }_{i}\right)=b_{0(\text { Lang } 2)}+h \cdot 0+j \cdot 0+0=b_{0(\text { Lang } 2)},
$$

To sum up, in SEM, the mean and the intercept of a variable coincide when the variable only receives factor effects.

\section{References}

1. Legkauskas, V.; Magelinskaite-Legkauskienè, Š. Importance of social competence at the start of elementary school for adjustment indicators a year later. Issues Educ. Res. 2019, 29, 1262-1276.

2. Jimerson, S.; Egeland, B.; Sroufe, L.A.; Carlson, B. A prospective longitudinal study of high school dropouts examining multiple predictors across development. J. Sch. Psychol. 2000, 38, 525-549. [CrossRef]

3. Ryan, A.; Shin, H. Peers, academics and teachers. In Handbook of Peer Interactions, Relationships and Groups, 2nd ed.; Bukowski, W.B., Laursen, B., Rubin, K.H., Eds.; Guilford Press: New York, NY, USA, 2018; pp. 637-656.

4. Moreno, J.L. Who Shall Survive? Beacon House, Inc.: New York, NY, USA, 1953. 
5. Blackhart, G.C.; Nelson, B.C.; Knowles, M.L.; Baumeister, R.F. Rejection elicits emotional reactions but neither causes immediate distress nor lowers self-esteem: A meta-analytic review of 192 studies on social exclusion. Personal. Soc. Psychol. Rev. 2009, 13, 269-309. [CrossRef]

6. Cillessen, A.H.N.; Bukowski, W.M.; Damon, W. Recent Advances in the Measurement of Acceptance and Rejection in the Peer System. New Dir. Child Adolesc. Dev. 2000, 2000, 27-53. [CrossRef]

7. Leary, M.R. Interpersonal Rejection; Oxford University Press: New York, NY, USA, 2001.

8. Coie, J.D.; Dodge, K.A.; Coppotelli, H. Dimensions and types of social status: A cross-age perspective. Dev. Psychol. 1982, 18, 557-570. [CrossRef]

9. Bukowski, W.M.; Sippola, L.; Hoza, B.; Newcomb, A.F. Pages from a sociometric notebook: An analysis of nomination and rating scale measures of acceptance, rejection, and social preference. New Dir. Child Adolesc. Dev. 2000, 2000, 11-26. [CrossRef] [PubMed]

10. García Bacete, F.J.; Cillessen, A.H.N. An adjusted probability method for the identification of sociometric status in classrooms. Front. Psychol. 2017, 8, 1836. [CrossRef]

11. Gommans, R.; Cillessen, A.H.N. Nominating under constraints. Int. J. Behav. Dev. 2015, 39, 77-86. [CrossRef]

12. Hartup, W.W. Social Relationships and Their Developmental Significance. Am. Psychol. 1989, 44, 120-126. [CrossRef]

13. Ollendick, T.H.; Greene, R.W.; Francis, G.; Baum, C.G. Sociometric Status: Its Stability and Validity Among Neglected, Rejected and Popular Children. J. Child Psychol. Psychiatry 1991, 32, 525-534. [CrossRef]

14. Gresham, F.M. Conceptual and Definitional issues in the Assessment of Children's Social Skills: Implications for Classifications and Training. J. Clin. Child Psychol. 1986, 15, 3-15. [CrossRef]

15. Stadtfeld, C.; Takács, K.; Vörös, A. The Emergence and Stability of Groups in Social Networks. Soc. Netw. 2020, 60, 129-145. [CrossRef]

16. Hummon, N.P.; Doreian, P. Some dynamics of social balance processes: Bringing Heider back into balance theory. Soc. Netw. 2003, 25, 17-49. [CrossRef]

17. Fay, A.J.; Jordan, A.H.; Ehrlinger, J. How Social Norms Promote Misleading Social Feedback and Inaccurate Self-Assessment. Soc. Personal. Psychol. Compass 2012, 6, 206-216. [CrossRef]

18. García Bacete, F.J.; Carrero Planes, V.E.; Marande, G.; Musitu Ochoa, G. Understanding rejection between first-and-second-grade elementary students through reasons expressed by rejecters. Front. Psychol. 2017, 8, 462. [CrossRef]

19. Labianca, G.; Brass, D.J. Exploring the social ledger: Negative relationships and negative asymmetry in social networks in organizations. Acad. Manag. Rev. 2006, 31, 596-614. [CrossRef]

20. Bisquerra, R. Universo de Emociones; PalauGea: Valencia, Spain, 2014.

21. Fredrickson, B.L. Positive Emotions Broaden and Build. Adv. Exp. Soc. Psychol. 2013, 47, 1-53. [CrossRef]

22. Taylor, S.E. Asymmetrical effects of positive and negative events: The mobilization-minimization hypothesis. Psychol. Bull. 1991, 110, 67-85. [CrossRef] [PubMed]

23. Mikami, A.Y. Parental Friendship Coachig Intervention Manual; University of Virginia: Charlottesville, VA, USA, 2010; Unpublished.

24. Parker, J.G.; Rubin, K.H.; Erath, S.A.; Wojslawowicz, J.C.; Buskirk, A.A. Peer relationships, child development, and adjustment: A developmental psychopathology perspective. In Developmental Psychopathology: Theory and Method, 2nd ed.; Cicchetti, D., Cohen, D.T., Eds.; John Wiley \& Sons, Inc.: Hoboken, NJ, USA, 2006; Volume 1, pp. 419-493.

25. DeWall, C.N.; Bushman, B.J. Social acceptance and rejection: The sweet and the bitter. Curr. Dir. Psychol. Sci. 2011, 20, 256-260. [CrossRef]

26. Parker, J.G.; Asher, S.R. Peer relations and later personal adjustment: Are low-accepted children at risk? Psychol. Bull. 1987, 102, 357-389. [CrossRef] [PubMed]

27. Ladd, G.W. Peer rejection, aggressive or withdrawn behavior, and psychological maladjustment from ages 5 to 12 : An examination of four predictive models. Child Dev. 2006, 77, 822-846. [CrossRef]

28. Gifford-Smith, M.E.; Brownell, C.A. Childhood peer relationships: Social acceptance, friendships, and peer networks. J. Sch. Psychol. 2003, 41, 235-284. [CrossRef]

29. Buhs, E.S.; Ladd, G.W.; Herald, S.L. Peer exclusion and victimization: Processes that mediate the relation between peer group rejection and children's classroom engagement and achievement? J. Educ. Psychol. 2006, 98, 1-13. [CrossRef]

30. Gerber, J.; Wheeler, L. On being rejected: A meta-analysis of experimental research on rejection. Perspect. Psychol. Sci. 2009, 4, 468-488. [CrossRef] [PubMed]

31. Ladd, G.W.; Troop-Gordon, W. The Role of Chronic Peer Difficulties in the Development of Children's Psychological Adjustment Problems. Child Dev. 2003, 74, 1344-1367. [CrossRef] [PubMed]

32. Wiseman, J.P.; Duck, S. Having and managing enemies: A very challenging relationship. In Confronting Relationship Challenges; Understanding Relationship Processes Series; Duck, S., Wood, J.T., Eds.; Sage Publications, Inc.: Thousand Oaks, CA, USA, 1995; Volume 5, pp. 43-72.

33. Coie, J.D.; Dodge, K.A. Continuities and changes in children's social status: A five-year longitudinal study. Merrill Palmer Q. 1983, 29, 261-282.

34. Salmivalli, C.; Isaacs, J. Prospective relations among victimization, rejection, friendlessness, and children's self- And peerperceptions. Child Dev. 2005, 76, 1161-1171. [CrossRef]

35. Will, G.J.; van Lier, P.A.C.; Crone, E.A.; Güroğlu, B. Chronic Childhood Peer Rejection is Associated with Heightened Neural Responses to Social Exclusion during Adolescence. J. Abnorm. Child Psychol. 2016, 44, 43-55. [CrossRef] 
36. García Bacete, F.J.; Marande, G.; Mikami, A.Y. Evaluation of a multi-component and multi-agent intervention to improve classroom social relationships among early elementary school-age children. J. Sch. Psychol. 2019, 77, 124-138. [CrossRef]

37. Bierman, K.L. Peer Rejection. Developmental, Processes and Intervention Strategies; The Guilford Press: New York, NY, USA, 2004.

38. Sandstrom, M.J.; Coie, J.D. A developmental perspective on peer rejection: Mechanisms of stability and change. Child Dev. 1999, 70, 955-966. [CrossRef]

39. De La Orden Hoz, A.; Jornet Meliá, J.M. La utilidad de las evaluaciones de sistemas educativos: El valor de la consideración del contexto. Bordon 2012, 64, 69-88.

40. Wentzel, K.R.; Jablansky, S.; Scalise, N.R. Peer Social Acceptance and Academic Achievement: A Meta-Analytic Study. J. Educ. Psychol. 2020. [CrossRef]

41. Ding, H.; Homer, M. Interpreting mathematics performance in PISA: Taking account of reading performance. Int. J. Educ. Res. 2020, 102, 1015-1066. [CrossRef]

42. Peng, P.; Lin, X.; Ünal, Z.E.; Lee, K.; Namkung, J.; Chow, J.; Sales, A. Examining the mutual relations between language and mathematics: A meta-analysis. Psychol. Bull. 2020, 146, 595-634. [CrossRef] [PubMed]

43. Guo, Q.; Zhou, J.; Feng, L. Pro-social behavior is predictive of academic success via peer acceptance: A study of Chinese primary school children. Learn. Individ. Differ. 2018, 65, 187-194. [CrossRef]

44. Wentzel, K.R.; Caldwell, K. Friendships, Peer Acceptance, and Group Membership: Relations to Academic Achievement in Middle School. Child Dev. 1997, 68, 1198-1209. [CrossRef] [PubMed]

45. Véronneau, M.H.; Vitaro, F.; Brendgen, M.; Dishion, T.J.; Tremblay, R.E. Transactional Analysis of the Reciprocal Links Between Peer Experiences and Academic Achievement From Middle Childhood to Early Adolescence. Dev Psychol. 2010, 46, 773-790. [CrossRef] [PubMed]

46. Wentzel, K.R.; Muenks, K. Peer influence on students' motivation, academic achievement, and social behavior. In Handbook of Social Influences in School Contexts: Social-Emotional, Motivation, and Cognitive Outcomes; Wentzel, K.R., Ramani., G.B., Eds.; Taylor and Francis Inc.: Milton Park, Oxfordshire, UK, 2016; pp. 13-30.

47. Juvonen, J.; Wentzel, K.R. Social Motivation: Understanding Children's School Adjustment; Cambridge University Press: New York, NY, USA, 1996.

48. Buhs, E.S.; Ladd, G.W. Peer rejection as an antecedent of young children's school adjustment: An examination of mediating processes. Dev. Psychol. 2001, 37, 550-560. [CrossRef] [PubMed]

49. Greenman, P.S.; Schneider, B.H.; Tomada, G. Stability and change in patterns of peer rejection: Implications for children's academic performance over time. Sch. Psychol. Int. 2009, 30, 163-183. [CrossRef]

50. García Bacete, F.J.; Jiménez, I.; Muñoz Tinoco, V.; Marande, G.; Monjas, M.I.; Sureda, I.; Martín Antón, L.J.; Ferrá Coll, P.; Sanchiz Ruiz, M.L. El Rechazo entre Iguales en su Contexto Interpersonal: Una Investigación con Niños y Niñas de Primer ciclo de Primaria; Davalos-Fletcher: Castellón, Spain, 2014.

51. González, J.; García Bacete, F.J. Sociomet. Programa para la Realización de Estudios Sociométricos; TEA Ediciones: Madrid, Spain, 2010.

52. Cillessen, A.H.N.; Bukowski, W.M. Sociometric perspectives. In Handbook of Peer Interactions, Relationships and Groups, 2nd ed.; Bukowski, W.B., Laursen, B., Rubin, K.H., Eds.; Guilford Press: New York, NY, USA, 2018; pp. 64-83.

53. Kokkinos, C.M.; Charalambous, K.; Davazoglou, A. Interpersonal teacher behaviour in primary school classrooms: A crosscultural validation of a Greek translation of the Questionnaire on Teacher Interaction. Learn. Environ. Res. 2009, 12, 101-114. [CrossRef]

54. Little, T.D. Longitudinal Structural Equation Modeling; Guildford: New York, NY, USA, 2013.

55. Meredith, W. Notes on factorial invariance. Psychometrika 1964, 29, 177-185. [CrossRef]

56. Rosel, J.; Plewis, I. Longitudinal data analysis with structural equations. Methodology 2008, 4, 37-50. [CrossRef]

57. Widaman, K.F.; Ferrer, E.; Conger, R.D. Factorial invariance within longitudinal structural equation models: Measuring the same construct across time. Child Dev. Perspect. 2010, 4, 10-18. [CrossRef]

58. IBM Corp. Released 2019. IBM SPSS Statistics for Windows; Version 26.0; IBM Corp: Armonk, NY, USA, 2019.

59. Bentler, P.M. EQS Structural Equations Program Manual; Multivariate Software Inc.: Encino, CA, USA, 2014.

60. Lee, I.A.; Preacher, K.J. Calculation for the Test of the Difference between Two Dependent Correlations with one Variable in Common [Computer Software]. Available online: http:/ / quantpsy.org (accessed on 21 May 2020).

61. Steiger, J.H. Tests for comparing elements of a correlation matrix. Psychol. Bull. 1980, 87, 245-251. [CrossRef]

62. Cohen, J.; Cohen, P.; West, S.; Aiken, L. Applied Multiple Regression/Correlation Analysis for the Behavioral Sciences, 3rd ed.; Routledge: New York, NY, USA, 2013. [CrossRef]

63. Rowntree, D.; Chiappa, C.; Vasco Montoya, E. Introducción a la Estadística: Un Enfoque no Matemático; Editorial Norma: Bogota, Colombia, 1984.

64. Kline, R.B. Principles and Practice of Structural Equation Modeling, 4th ed.; Guilford: New York, NY, USA, 2016.

65. Satorra, A.; Bentler, P.M. Corrections to test statistics and standard errors in covariance structure analysis. In Latent Variables Analysis: Applications for Developmental Research; von Eye, A., Clogg, C.C., Eds.; Sage Publications Inc.: New York, NY, USA, 1994; pp. 399-419.

66. Burnham, K.P.; Anderson, D.R.; Huyvaert, K.P. AIC model selection and multimodel inference in behavioral ecology: Some background, observations, and comparisons. Behav. Ecol. Sociobiol. 2011, 65, 23-35. [CrossRef] 
67. Batra, S. The Psychosocial Development of Children: Implications for Education and Society-Erik Erikson in Context. Contemp. Educ. Dialogue 2013, 10, 249-278. [CrossRef]

68. Méndez Alonso, D.; Méndez Giménez, A.; Fernández-Rio, F.J. Análisis y valoración del proceso de incorporación de las Competencias Básicas en Educación Primaria. Rev. Investig. Educ. 2015, 33, 233-246. [CrossRef]

69. Gnambs, T.; Hanfstingl, B. The decline of academic motivation during adolescence: An accelerated longitudinal cohort analysis on the effect of psychological need satisfaction. Educ. Psychol. 2016, 36, 1698-1712. [CrossRef]

70. Álvarez Pérez, L.; González-Pienda, J.; Núñez Pérez, J.; González, P.; González-Pumariega Solis, S.; Roces, C. ¿Cómo explicar tanto fracaso en el aprendizaje de las matemáticas?. Revista Galego-Portuguesa de Psicoloxía e Educación: Revista de Estudios e Investigación en Psicología y Educación; Universidade da Coruña: A Coruña, Spain, 2003; pp. 349-358.

71. Gottfried, A.E.; Marcoulides, G.A.; Gottfried, A.W.; Oliver, P.H.; Guerin, D.W. Multivariate latent change modeling of developmental decline in academic intrinsic math motivation and achievement: Childhood through adolescence. Int. J. Behav. Dev. 2007, 31, 317-327. [CrossRef]

72. Newsom, J.T. Longitudinal Structural Equation Modeling: A Comprehensive Introduction; Routledge: New York, NY, USA, 2015.

73. Bellmore, A.D.; Cillessen, A.H.N. Children's meta-perceptions and meta-accuracy of acceptance and rejection by same-sex and other-sex peers. Pers. Relatsh. 2003, 10, 217-234. [CrossRef]

74. Croce, R.C.; Boseovski, J.J. Trait or testimony? Children's preferences for positive informants. J. Exp. Child Psychol. 2020, 190, 104726. [CrossRef] [PubMed]

75. Wentzel, K.R. Peer Relationships, Motivation, and Academic Performance at School. In Handbook of Competence and Motivation Theory and Application, 2nd ed.; Elliot, A.J., Dweck, C.S., Yeager, D.S., Eds.; Guilford Press: New York, NY, USA, 2017 ; pp. 586-603.

76. Vecina Jiménez, M.L. Emociones positivas. In Papeles del psicólogo. Colegio Oficial de Psicólogos de Madrid; Infocop: Madrid, Spain, 2006; Volume 27, pp. 9-17. Available online: http:/ / dialnet.unirioja.es/servlet/oaiart?codigo=1417553 (accessed on 17 September 2020).

77. Ault, C.D. Measuring Peer Relationships during Childhood Exploring the Benefits of Using Peer Nomination. In Conducting Research in Developmental Psychology: A Topical Guide for Research Methods Utilized Across the Lifespan; Jones, N., Platt, M., Mize, K., Hardin, J., Eds.; Routledge: New York, NY, USA, 2020; pp. 148-155.

78. Thomson, S. Achievement at school and socioeconomic background-An educational perspective. Npj Sci. Learn. $2018,3,5$. [CrossRef]

79. Voight, A.; Shinn, M.; Nation, M. The Longitudinal Effects of Residential Mobility on the Academic Achievement of Urban Elementary and Middle School Students. Educ. Res. 2012, 41, 385-392. [CrossRef]

80. Sirin, S.R. Socioeconomic Status and Academic Achievement: A Meta-Analytic Review of Research. Rev. Educ. Res. 2005, 75, 417-453. [CrossRef]

81. Leary, M.R.; Koch, E.J.; Hechenbleikner, N.R. Emotional responses to interpersonal rejection. In Interpersonal Rejection; Oxford University Press: New York, NY, USA, 2001; pp. 145-166.

82. Evans, I.M.; DiBenedetto, A. Pathways to School Dropout A Conceptual Model for Early Prevention. Spec. Serv. Sch. 1991, 6, 63-80.

83. Cerda, G.; Pérez, C.; Elipe, P.; Casas, J.A.; Del Rey, R. Convivencia escolar y su relación con el rendimiento académico. Rev. Psicodidáctica 2019, 24, 46-52.

84. Barrera, A.E.; Schuster, B. Cross-domain effects of achievement goals: Social costs and benefits. Eur. J. Psychol. Educ. 2018, 33, 319-336. [CrossRef] 